\title{
Four New Species of Dryocosmus gallwasps from Taiwan (Hymenoptera: Cynipidae: Cynipini)
}

\author{
George Melika, ${ }^{1}$ Chang-Ti Tang, ${ }^{2}$ James A. Nicholls, ${ }^{3}$ Man-Miao Yang, ${ }^{2}$ and Graham N. Stone ${ }^{3}$ \\ ${ }^{1}$ Pest Diagnostic Laboratory, Plant Protection \& Soil Conservation Directorate, Governmental Office for County Vas, \\ Ambrozy Setany 2, 9762 Tanakajd, Hungary \\ ${ }^{2}$ Department of Entomology, National Chung Hsing University, Taichung 40227, Taiwan \\ ${ }^{3}$ Institute of Evolutionary Biology, University of Edinburgh, King's Buildings, West Mains Road, Edinburgh EH9 3JT, UK \\ Correspondence should be addressed to George Melika, melikageorge@gmail.com \\ Received 11 January 2011; Accepted 27 February 2011 \\ Academic Editors: R. Castiglia, S. P. Henzi, and T. Monnin \\ Copyright () 2011 George Melika et al. This is an open access article distributed under the Creative Commons Attribution License, \\ which permits unrestricted use, distribution, and reproduction in any medium, provided the original work is properly cited. \\ Four new species of oak gallwasps of the genus Dryocosmus: D. pentagonalis, D. triangularis, D. carlesiae, and D. testisimilis are \\ described from Taiwan. They induce galls on one species of Castanopsis and one species of Lithocarpus (Fagaceae). Data on the \\ diagnosis, distribution, and biology of the four new species is given. A key for Dryocosmus species identification of Taiwan is \\ provided. Final comments discuss the polyphyletic nature of the Dryocosmus genus, emphasizing the urgent need for its revision.
}

\section{Introduction}

The cynipid gallwasp fauna of the Eastern Palaearctic and Oriental region is poorly known: only 35 valid species are recognised from the Eastern Palaearctic, mostly from Japan and the Russian Far East, and only a few oak gallwasp species have yet been described or mentioned as "cynipid gallwasp" from the Oriental region [1-3]. Eleven gall morphotypes attributed to cynipids have been described from Taiwan $[4,5]$, from which only three valid species are currently known: Andricus formosanus Tang et al. [6], Trichagalma formosana Melika \& Tang, and Cerroneuroterus vonkuenburgi (Dettmer), all of which are associated with the subgenus Quercus within the genus Quercus [3].

The family Fagaceae in Eastern Asia, including Taiwan, is represented by five taxa which serve as hosts for oak gallwasps (Cynipini): Castanea Miller (2 species in Taiwan), Castanopsis (D.Don) (8 species in Taiwan), Lithocarpus Blume (=Pasania (Miq.)) (15 species in Taiwan), Quercus L. subgenus Cyclobalanopsis (13 species in Taiwan), and Quercus subgenus Quercus (10 species in Taiwan) [7, 8]. Thirty-four of the 35 known valid oak gallwasp species of the Eastern Palaearctic and Oriental region are galling Quercus subgenus Quercus. Nine different cynipid gall morphotypes (all undescribed species from the point of view of ICZN) from Japan are known to associate with Quercus subgenus Cyclobalanopsis (8 with Quercus glauca Thunb. and one with Q. gilva Blume) and one cynipid gall morphotype with Castanopsis cuspidata Schottky [9]. Of the eleven cynipid gall morphotypes described from Taiwan $[4,5]$, only three gall morphotypes are associated with Quercus subgenus Quercus; the remainder are associated with subgenus Cyclobalanopsis and non-Quercus host plants. However, no valid species yet are known from Quercus subgenus Cyclobalanopsis, Castanopsis, and Lithocarpus. One well-known and widely introduced species, Dryocosmus kuriphilus Yasumatsu, is known to associate with different species of Castanea. One species with dubious status, Neuroterus haasi Kieffer, described from India, is known to associate with Lithocarpus elegans (Blume) (syn. Quercus spicata Sm.) [3, 10, 11]. Based on the known deep phylogenetic split between gallwasp taxa galling oaks in the sections Cerris and Quercus (s.s.) within the subgenus Quercus [12], we would suspect an even deeper split between gallwasp taxa galling different subgenera of Quercus (Cyclobalanopsis and Quercus) and those associated with non-Quercus host plant genera (Castanopsis and Lithocarpus).

In the Holarctic, 23 valid species are known from the genus Dryocosmus Giraud: six species are known from Europe and Iran, all associated with only section Cerris 

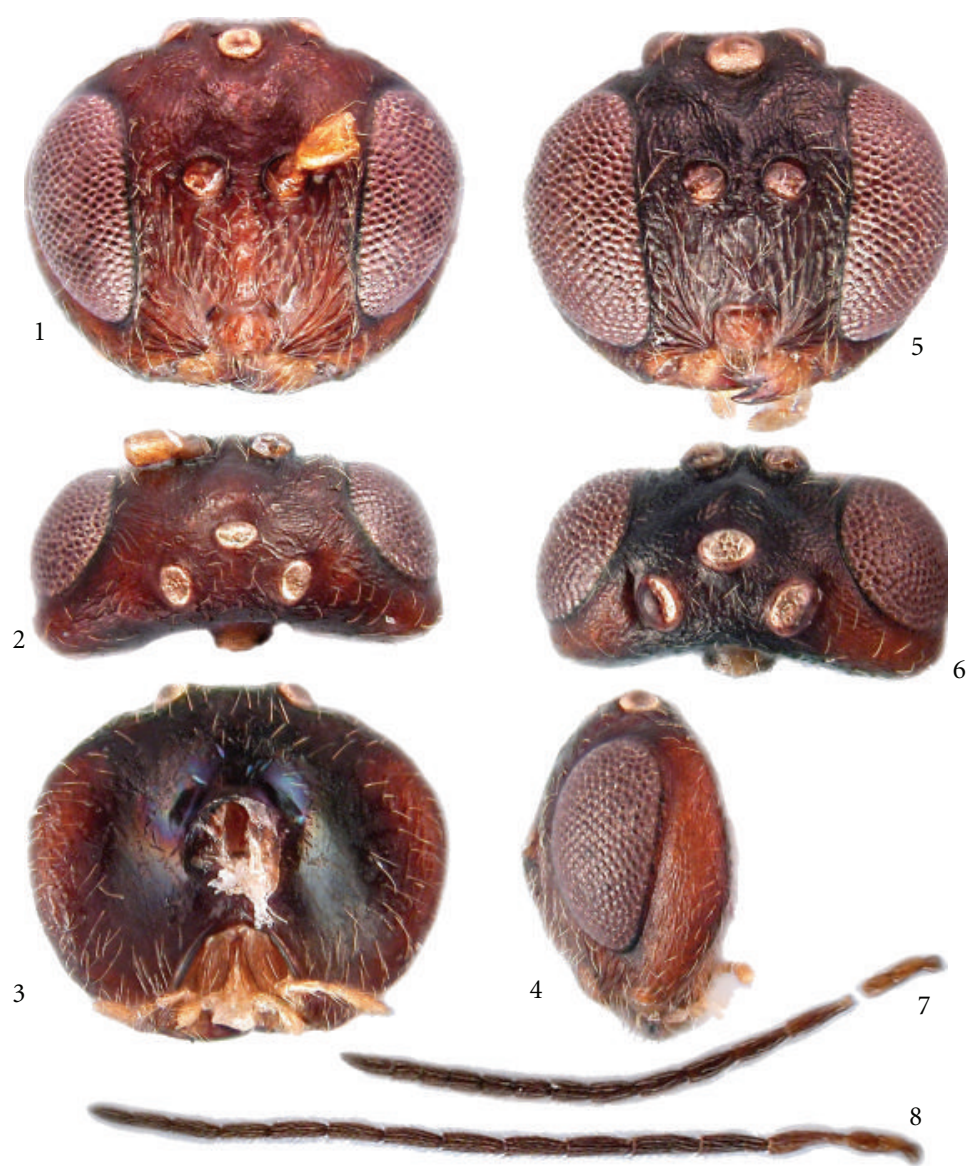

Figure 1: Drycosmus pentagonalis, new species. (1-4) Head, female: (1) anterior view; (2) dorsal view; (3) posterior view; (4) lateral view. (5-6) Head, male: (5) anterior view; (6) dorsal view. (7-8) Antenna: (7) female, (8) male.

oaks [3, 13], and 16 from across the continent of North America, galling the sections Lobatae (red oaks; 13 species) and Protobalanus (golden-cup oaks; 1 species: D. assymetricus (Kinsey), with two variations [14]) within Quercus subgenus Quercus, and the non-oak genus Chrysolepis (2 species: D. castanopsidis (Beutenm.) and D. rileypokei Morita \& Buffington) $[15,16]$. Currently, only one species, $D$. kuriphilus Yasumatsu, is known from the Eastern Palaearctic (China, Korea, Japan, Nepal; [2]) galling Castanea species; however, this species has been introduced into the eastern US [17] and also recently into Europe [18].

We describe four new Dryocosmus species from Taiwan, three of which (D. pentagonalis, D. triangularis, and D. carlesiae) are associated with Castanopsis carlesii (Hemsl.) and one species (D. testisimilis) with Lithocarpus uraianus (Hayata) Hayata (= Castanopsis uraiana (Hayata) Kanehira).

\section{Materials and Methods}

The material examined was reared from galls on different Castanopsis or Lithocarpus species, collected from different counties of Taiwan.

We follow the current terminology of morphological structures [13, 19]. Abbreviations for forewing venation follow Ronquist and Nordlander [20], cuticular surface terminology follows that of Harris [21]. Measurements and abbreviations used here include: F1-F12 and 1st and subsequent flagellomeres; POL (postocellar distance) is the distance between the inner margins of the posterior ocelli; OOL (ocellar-ocular distance) is the distance from the outer edge of a posterior ocellus to the inner margin of the compound eye; LOL is the distance between lateral and frontal ocelli. The width of the forewing radial cell is measured from the margin of the wing to the Rs vein.

Images of wasp anatomy were produced with a digital Nikon Coolpix 4500 camera attached to a Leica DMLB compound microscope, followed by processing in CombineZP (Alan Hadley; a software package that makes possible the construction of an image with increased depth of field) and Adobe Photoshop 6.0.

The type material is deposited in the following institutions: NMNS, National Museum of Natural Science, Taichung, Taiwan (curator Mei-Ling Chan); PDL, Pest Diagnostic Laboratory (the former Systematic Parasitoid Laboratory, SPL), Tanakajd, Hungary (curator G. Melika); NCHU, collection of the Department of Entomology, National Chung Hsing University, Taichung, Taiwan (curator ChangTi Tang); USNM, U.S. National Museum of Natural History, 


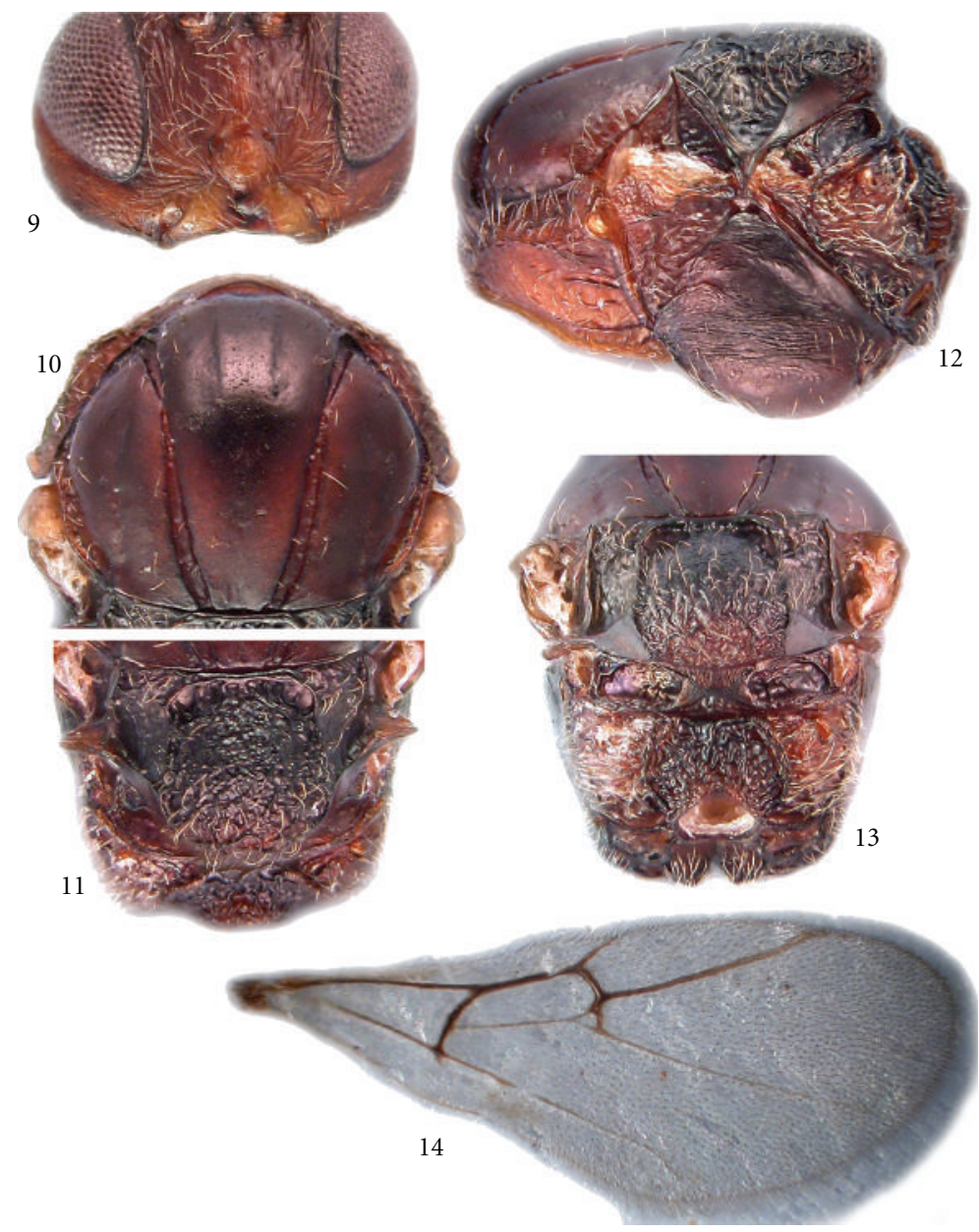

Figure 2: Drycosmus pentagonalis, new species, female: (9) clypeus and lower face, anterior view; (10) mesoscutum, dorsal view; (11) mesoscutellum, dorsal view; (12) mesosoma, lateral view; (13) metascutellum and propodeum, posterodorsal view; (14) forewing.

Smithsonian Institution, Washington, DC, USA (curator Matthew Buffington).

\subsection{Dryocosmus pentagonalis Melika \& Tang, New Species} Figures 1, 2, and 3

\subsubsection{Type Material}

Holotype Female. TAIWAN, Taitung County, Daren Forest Station, Daren Township, ex Castanopsis carlesii, leg. ChangTi Tang, 28.III.2010. adult em. 06.IV.2010. PARATYPES: 5 females and 6 males: 3 male paratypes: TAIWAN, Taitung County, Daren Forest Station, Daren Township, ex C. carlesii, leg. Chang-Ti Tang, 14.III.2010. adult em. 20.III.2010; 1 female paratype: TAIWAN, Taitung County, Daren Forest Station, Daren Township, ex C. carlesii, leg. Chang-Ti Tang, 14.III.2010. adult em. 24.III.2010; 1 female paratype: TAIWAN, Taitung County, Daren Forest Station, Daren Township, ex C. carlesii, leg. Chang-Ti Tang, 14.III.2010. adult em. 25.III.2010; 2 female and 2 male paratypes: TAIWAN, Taitung County, Daren Forest Station, Daren Township, ex C. carlesii, leg. Chang-Ti Tang, 14.III.2010. adult em. 26.III.2010; 1 female paratype: TAIWAN, Taitung County, Daren Forest Station, Daren Township, ex C. carlesii, leg. Chang-Ti Tang, 14.III.2010. adult em. 02.IV.2010. The holotype female, 1 female and 1 male paratypes are deposited in NMNS, 2 female and 2 male paratypes in PDL, 1 female and 1 male paratypes in USNM; 1 female and 2 male paratypes in NCHU.

2.1.2. Etymology. The species named after the peculiar pentagonal shape of the gall.

2.1.3. Diagnosis. The four described Dryocosmus species morphologically fall into two distinct groups: $D$. pentagonalis with $D$. triangularis, while D. carlesiae most closely resembles $D$. testisimilis (see the key to species below for main morphological differences). Dryocosmus pentagonalis closely resembles $D$. triangularis, however, in $D$. pentagonalis the scape + pedicel in the female antenna $1.1 \mathrm{x}$ longer than F1, in the male antenna the pedicel is definitely shorter than the scape, while in D. triangularis F1 in the female antenna shorter than the scape + pedicel, in the male the pedicel nearly as long as the scape. See also the key to species below. 

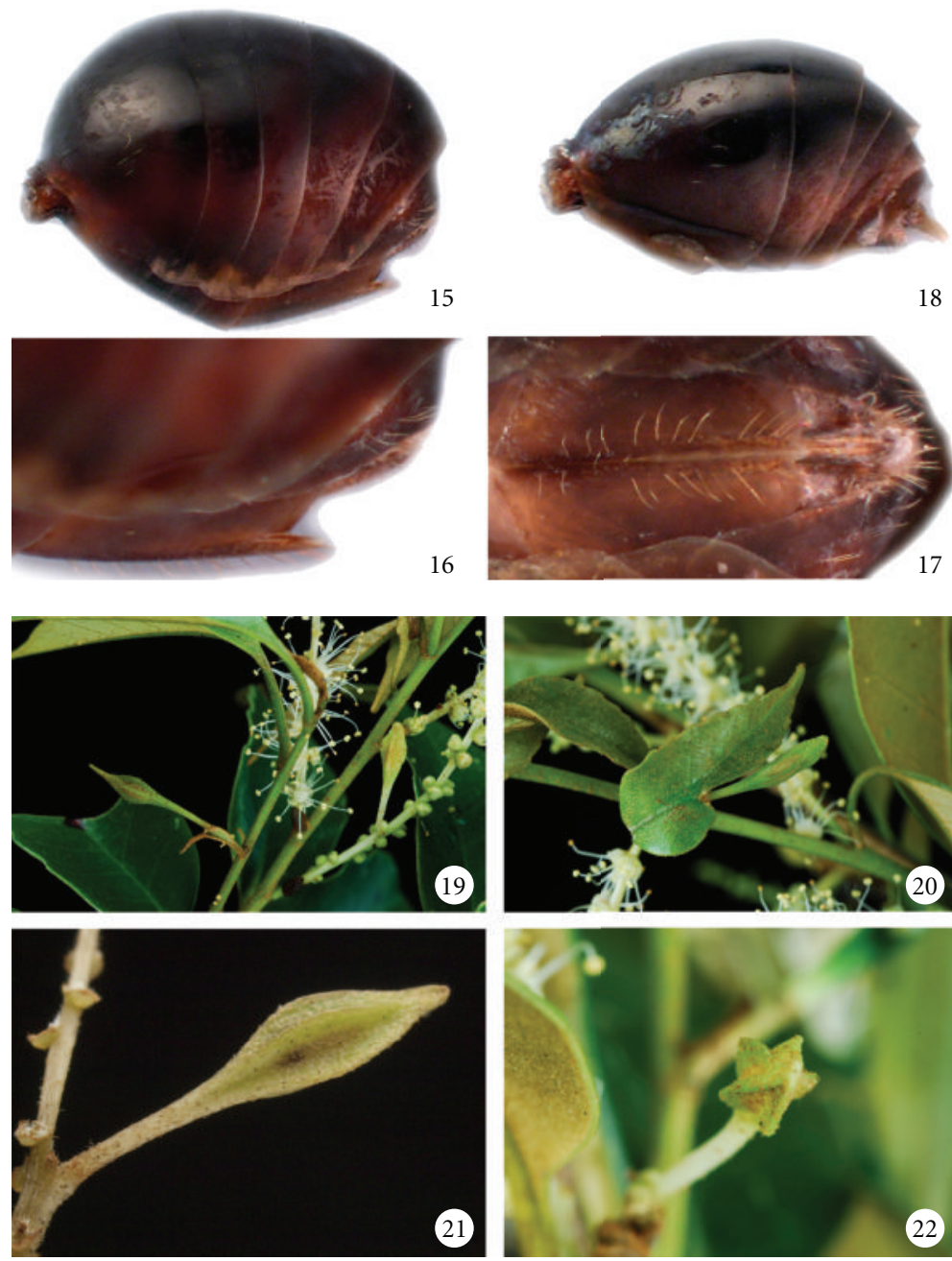

Figure 3: Drycosmus pentagonalis, new species, female: (15) metasoma, female, lateral view. (16-17) Ventral spine of hypopygium, female: (16) lateral view; (17) ventral view. (19-22) Gall: (19) galls on catkins, general view; (20) gall on leaf; (21) close-up of a gall, lateral view; (22) close-up of gall, view from the gall top $((19,20,22)$ by Chang-Fu Wu; (21) by Chang-Ti Tang).

\subsubsection{Description}

Female. Head anteriorly and laterally dark brown to chestnut brown; posteriorly, especially postocciput, postgena and postgenal bridge dark brown to black; labial and maxilly palps yellow; antenna yellow to dirty yellow, especially flagellomeres much darker dorsally; mesosoma chestnut brown to brown, pronotum laterally always lighter; mesoscutellum dark brown to black; metapleuron and central propodeal area always slightly darker than rest of mesosoma; legs uniformly yellow; metasoma dark brown, usually dorsally darker than laterally.

Head alutaceous, with sparse white setae, more dense on lower face, $2.1 \mathrm{x}$ broader than long from above; $1.2 \mathrm{x}$ broader than high in anterior view and slightly broader than mesosoma. Gena alutaceous, not broadened behind eye, 2.0x narrower than cross-diameter of eye, invisible in anterior view. Malar space alutaceous, with striae radiating from clypeus and reaching eye; height of eye $3.7 x$ longer than length of malar space. Compound eyes slightly converging ventrally. $\mathrm{POL} 1.4 \mathrm{x}$ longer than $\mathrm{OOL}$; OOL $1.5 \mathrm{x}$ longer than diameter of lateral ocellus, 1.6x longer than LOL; ocelli ovate, all three equal in length. Transfacial distance $1.1 \mathrm{x}$ longer than height of eye and 1.5x longer than height of lower face (distance between antennal rim and ventral margin of clypeus); diameter of antennal torulus $1.5 \mathrm{x}$ longer than distance between them, distance between torulus and eye margin only slightly greater than diameter of torulus. Lower face alutaceous, with striae radiating from clypeus and extending nearly to lower level of antennal rim, with elevated median area. Clypeus rectangular, flat, slightly broader than high, alutaceous, with deep anterior tentorial pits, distinct epistomal sulcus, and clypeo-pleurostomal line; ventrally rounded and not incised medially. Frons alutaceous, with deep smooth and shiny impression below median ocellus; vertex and occiput alutaceous with some delicate short irregular striae; interocellar area delicately coriaceous, slightly elevated. Postgena smooth, shiny, postocciput around occipital foramen impressed, smooth, shiny; posterior tentorial pits large, deep, elongate; postgenal bridge at least $2.0 \mathrm{x}$ 


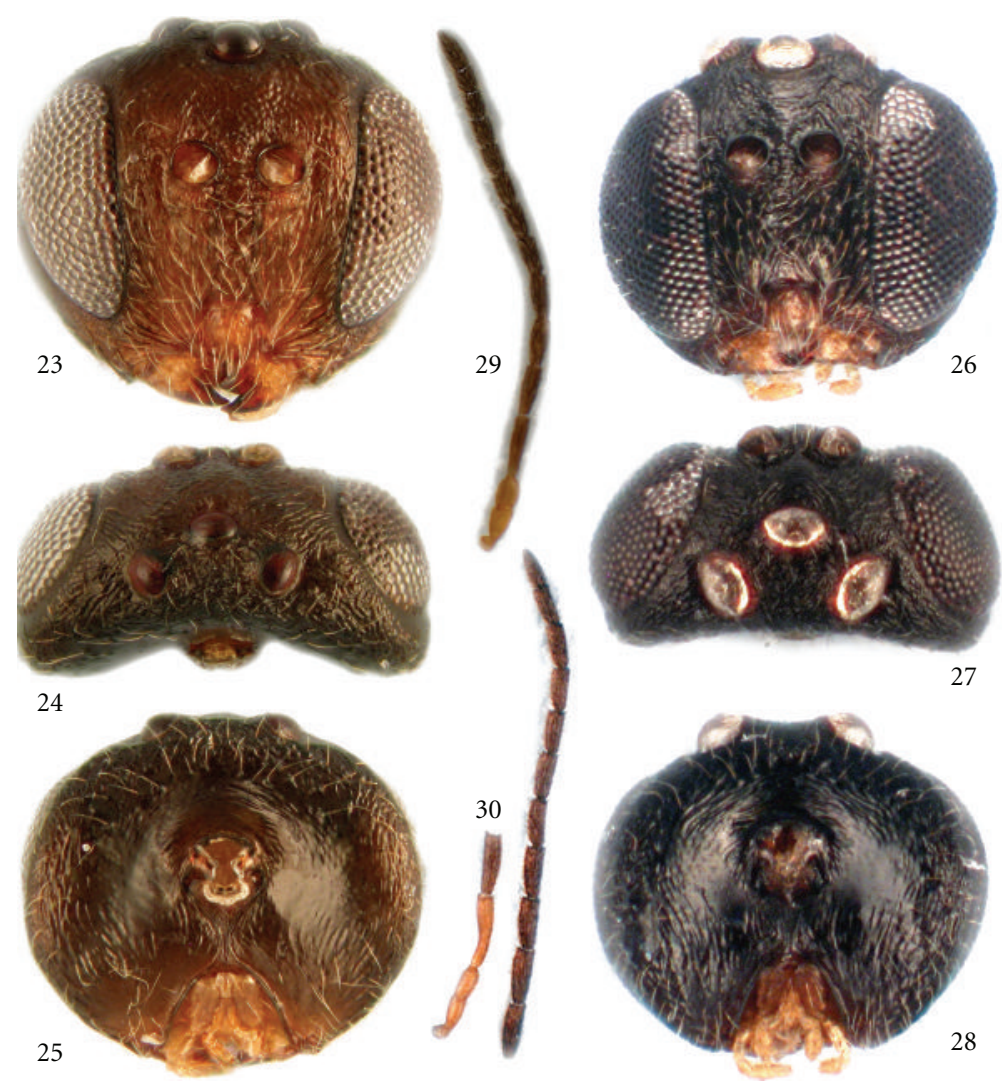

Figure 4: Drycosmus triangularis, new species. (23-25) Head, female: (23) anterior view; (24) dorsal view; (25) posterior view. (26-28) Head, male: (26) anterior view, (27) dorsal view, (28) posterior view. (29-30) Antenna: (29) female, (30) male.

higher than broad, lower part narrowed to a stripe; occipital foramen very slightly higher or equal to height of postgenal bridge, around 1.3x shorter than height of oral foramen. Antenna with 12 distinct flagellomeres (or 13, indistinct suture between F13 and F12 visible in some individuals), longer than head + mesosoma; pedicel 1.7 times as long as broad, F1 1.2x shorter than length of scape + pedicel, $1.15 \mathrm{x}$ longer than F2, F2 only slightly longer than F3, F3 = F4, F5F11 shorter than F4 and nearly equal in length; fused F12 + F13 1.8x longer than F11; placodeal sensilla on F1-F12, in numerous rows.

Mesosoma longer than high in lateral view. Pronotum smooth, shiny; with few white setae and with irregular delicate wrinkles laterally, emarginate along lateral edge, followed by deep longitudinal invagination. Anterior rim of pronotum narrow, emarginate; propleuron alutaceous, with few setae, strongly concave in mediocentral part. Mesoscutum smooth, shiny; nearly as long as broad (width measured across basis of tegulae); notauli complete, deeply impressed for full length; median mesoscutal line absent; anterior parallel and parapsidal lines not impressed, hardly traceable; parascutal carina broad, anteriorly reaching notauli. Transscutal articulation deep, distinct. Mesoscutellum only slightly longer than broad, rectangular, with parallel sides; shorter than mesoscutum, uniformly coriaceous, overhanging metanotum; scutellar foveae transverse ovate, with shiny bottom and few wrinkles on it, divided by central elevated area which only slightly narrower than width of fovea (in some individuals foveae indistinctly separated by central elevated area and form a transverse impression along anterior margin of mesoscutellum). Mesopleuron, including speculum, smooth, shiny, with few white setae and irregular delicate wrinkles which forming a transverse line bent in mid height and going across entire width of mesopleuron; mesopleural triangle shiny, with few white setae and some delicate irregular short wrinkles. Metapleural sulcus reaching mesopleuron slightly above half height; preaxilla delicately coriaceous, shiny; dorsal and lateral axillar areas shiny, smooth, with few setae; axillar carina broad, with longitudinal striae; subaxillular bar narrow, smooth, shiny, in most posterior end slightly higher than height of metanotal trough. Metascutellum uniformly coriaceous, slightly higher than height of smooth, shiny ventral impressed area; metanotal trough smooth, shiny, without setae. Lateral propodeal carinae distinct, lyre-shaped, bent outwards at mid height, central propodeal area shiny, with numerous delicate irregular wrinkles; lateral propodeal area coriaceous, with dense white setae; nucha very short, with delicate longitudinal sulci dorsolaterally and laterally.

Forewing as long or slightly longer than body, with distinct brown veins, margin with long dense cilia; radial cell $3.75 x$ longer than broad, R1 and Rs reaching wing margin; areolet large, triangular, well-delimited by distinct veins; Rs $+\mathrm{M}$ well-pigmented, reaching basalis in the lower third. 


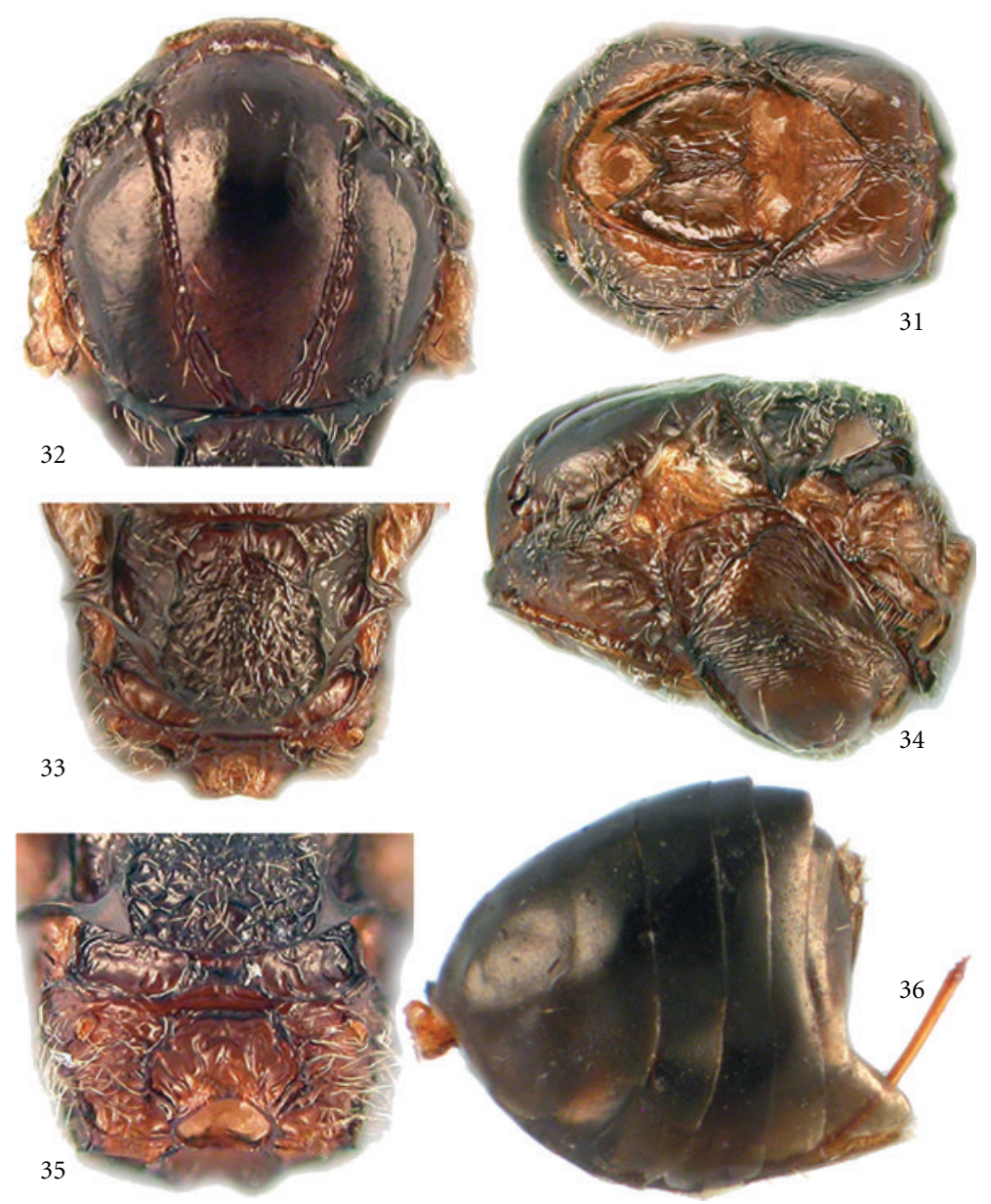

FIGURE 5: Drycosmus triangularis, new species, female: (31) pronotum and propleura, anterior view; (32) mesoscutum, dorsal view; (33) mesoscutellum, dorsal view; (34) mesosoma, lateral view; (35) metascutellum and propodeum, posterodorsal view; (36) metasoma, lateral view.

Tarsal claws simple, without basal lobe. Metasoma slightly shorter than head + mesosoma, slightly longer than high in lateral view, smooth, shiny, without setae; only 2 nd metasomal tergites laterally with very few white setae; 2 nd tergite extending to $1 / 3$ length of metasoma; prominent part of ventral spine of hypopygium short, nearly 2.0x longer than broad in ventral view, with long white setae, extending beyond apex of spine but never forming a tuft. Body length $2.3-2.6 \mathrm{~mm}(n=6)$.

Male. The colour pattern of the body the same as in female but usually much darker to black. Similar to female but compound eyes bigger and thus frons and lower face narrower than in female; also ocelli much bigger. Antenna longer than body, with 13 flagellomeres, proximal half of F1 broader than basal half, curved and excavated. Body length 2.1-2.4 $\mathrm{mm}(n=6)$.

2.1.5. Gall (Figure 3(19, 20, 21, 22). The gall closely resembles the asexual galls of three Western Palaearctic Andricus species: A. callidoma (Hartig), A. malpighii (Adler) and A. seminationis (Giraud); structurally the last one is the most similar. Galls are forming buds, catkins and young leaves. On catkins this gall causes thickening of the petiole, with the base of the gall inserted in a shallow depression. Unilocular. An elongated, spindle-shaped gall reaching a length of $8-10 \mathrm{~mm}$ and a diameter of $2-4 \mathrm{~mm}$ when mature. The gall is attached by a stalk of variable length (commonly $4-12 \mathrm{~mm}$ ). The main body of the gall is marked with longitudinal ribs, usually five, and thus from the top view the gall is star-shaped. Initially green, with brown spots. The whole gall becomes brownish or greenish as the same color with young leaf as it matures. The central part of the gall is yellowish brown in between brownish longitudinal ribs, showing the position of the inner larval chamber. Pubescent when young, especially the tip with longer whitish hairs. Wall thin and very slightly woody, with a relatively large single inner chamber.

2.1.6. Biology. The sexual generation galls Castanopsis carlesii (Hemsl.). Galls appear on the tree from early March, mature by mid-March, and adults emerge in late March to the first week of April. The asexual generation is unknown.

\subsubsection{Distribution. Taiwan, Taitung County (Figure 13).}



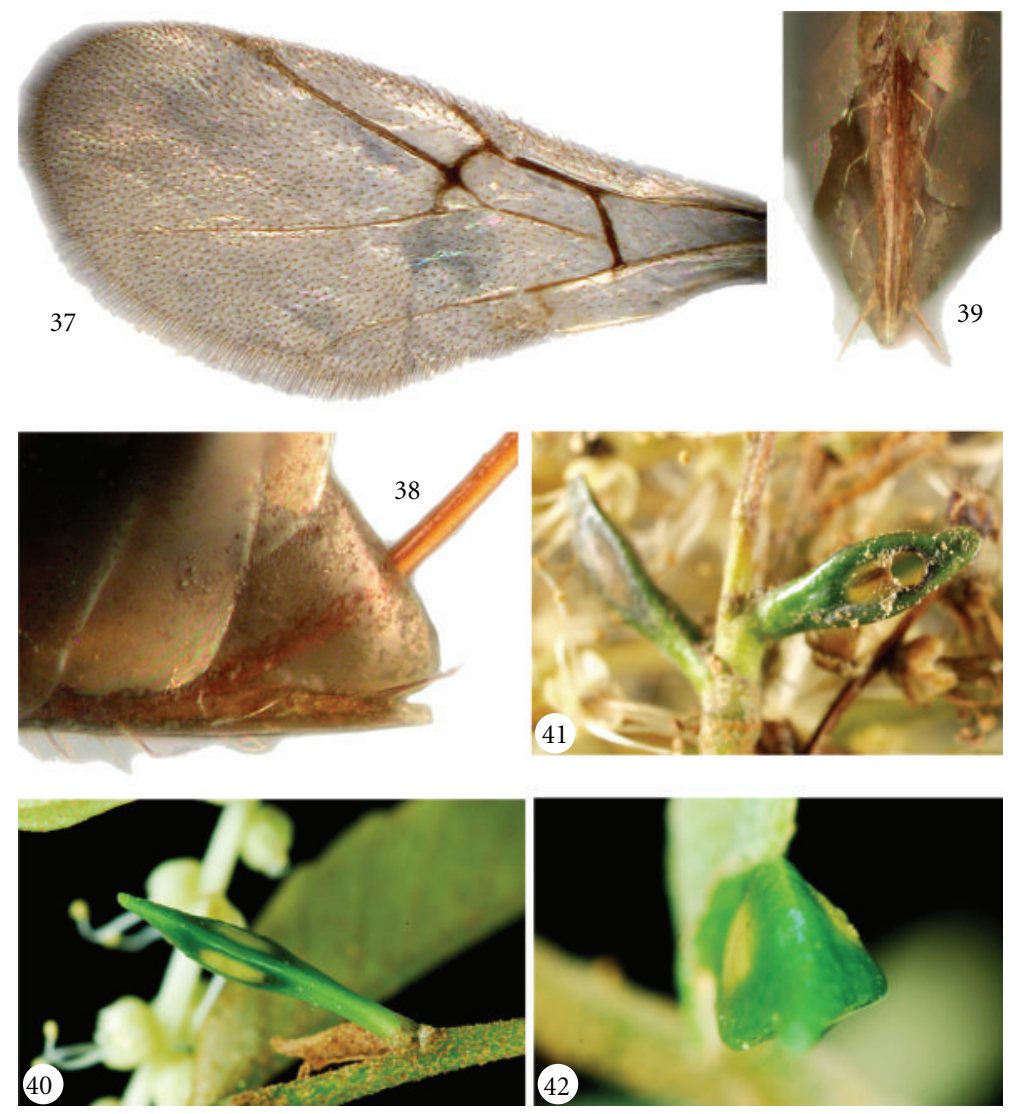

Figure 6: Drycosmus triangularis, new species. (37-39) Female: (37) forewing; (38-39) ventral spine of hypopygium, female: (38) lateral view, (39) ventral view. (40-42) Galls: (40) close-up of a gall, lateral view; (41) close-up of gall, with emerging hole; (42) close-up of gall, view from the gall top $((40,42)$ by Chang-Fu Wu; $(41)$ by Chang-Ti Tang).

\subsection{Dryocosmus triangularis Melika \& Tang, New Species Figures 4, 5, and 6}

\subsubsection{Type Material}

Holotype Female. TAIWAN, Taitung County, Dawu Township, ex Castanopsis carlesii, 13.III.2010. leg. Chang-Ti Tang. adult em. 26.III.2010. PARATYPES: 18 females and 14 males: 1 female and 2 male paratypes with the same labels as the holotype; 1 female paratype: TAIWAN, Taitung County, Dawu Township, ex C. carlesii, leg. Chang-Ti Tang, 02.IV.2009. adult em. 09.IV.2009; 1 female paratype: TAIWAN, Taitung County, Dawu Township, ex C. carlesii, leg. Chang-Ti Tang, 02.IV.2009. adult em. 11.IV.2009; 1 female paratype: TAIWAN, Taitung County, Dawu Township, ex $C$. carlesii, leg. Chang-Ti Tang, 02.IV.2009. adult em. 15.IV.2009; 2 male paratypes: TAIWAN, Taitung County, Dawu Township, ex C. carlesii, leg. Chang-Ti Tang, 13.III.2010. adult em. 18.III.2010; 2 female paratypes: TAIWAN, Taitung County, Dawu Township, ex C. carlesii, leg. Chang-Ti Tang, 13.III.2010. adult em. 19.III.2010; 2 female and 1 male paratypes: TAIWAN, Taitung County, Dawu Township, ex C. carlesii, leg. Chang-Ti Tang, 13.III.2010. adult em. 22.III.2010; 2 female and 2 male paratypes: TAIWAN, Taitung County, Dawu Township, ex C. carlesii, leg. ChangTi Tang, 13.III.2010. adult em. 23.III.2010; 2 female and 2 male paratypes: TAIWAN, Taitung County, Dawu Township, ex C. carlesii, leg. Chang-Ti Tang, 13.III.2010. adult em. 24.III.2010; 3 female and 1 male paratypes: TAIWAN, Taitung County, Dawu Township, ex C. carlesii, leg. ChangTi Tang, 13.III.2010. adult em. 25.III.2010; 2 male paratypes: TAIWAN, Taitung County, Daren Forest Station, Daren Township, ex C. carlesii, leg. Chang-Ti Tang, 14.III.2010. adult em. 22.III.2010; 1 female and 2 male paratypes: TAIWAN, Taitung County, Daren Forest Station, Daren Township, ex C. carlesii, leg. Chang-Ti Tang, 14.III.2010. adult em. 23.III.2010; 1 female paratype: TAIWAN, Taitung County, Dawu Township, ex C. carlesii, leg. Chang-Ti Tang, 27.III.2010. adult em. 29.III.2010; 2 female paratypes: TAIWAN, Taitung County, Dawu Township, ex C. carlesii, leg. Chang-Ti Tang, 27.III.2010. adult em. 30.III.2010. The holotype female, 5 female and 3 male paratypes are deposited in NMNS, 5 female and 4 male paratypes in PDL, 2 female and 2 male paratypes in USNM, 6 female and 5 male paratypes in NCHU.

2.2.2. Etymology. The species named after the triangularpyramid shape of the gall.

2.2.3. Diagnosis. Most closely resembles $D$. pentagonalis (see diagnosis to D. pentagonalis and the key to species). 


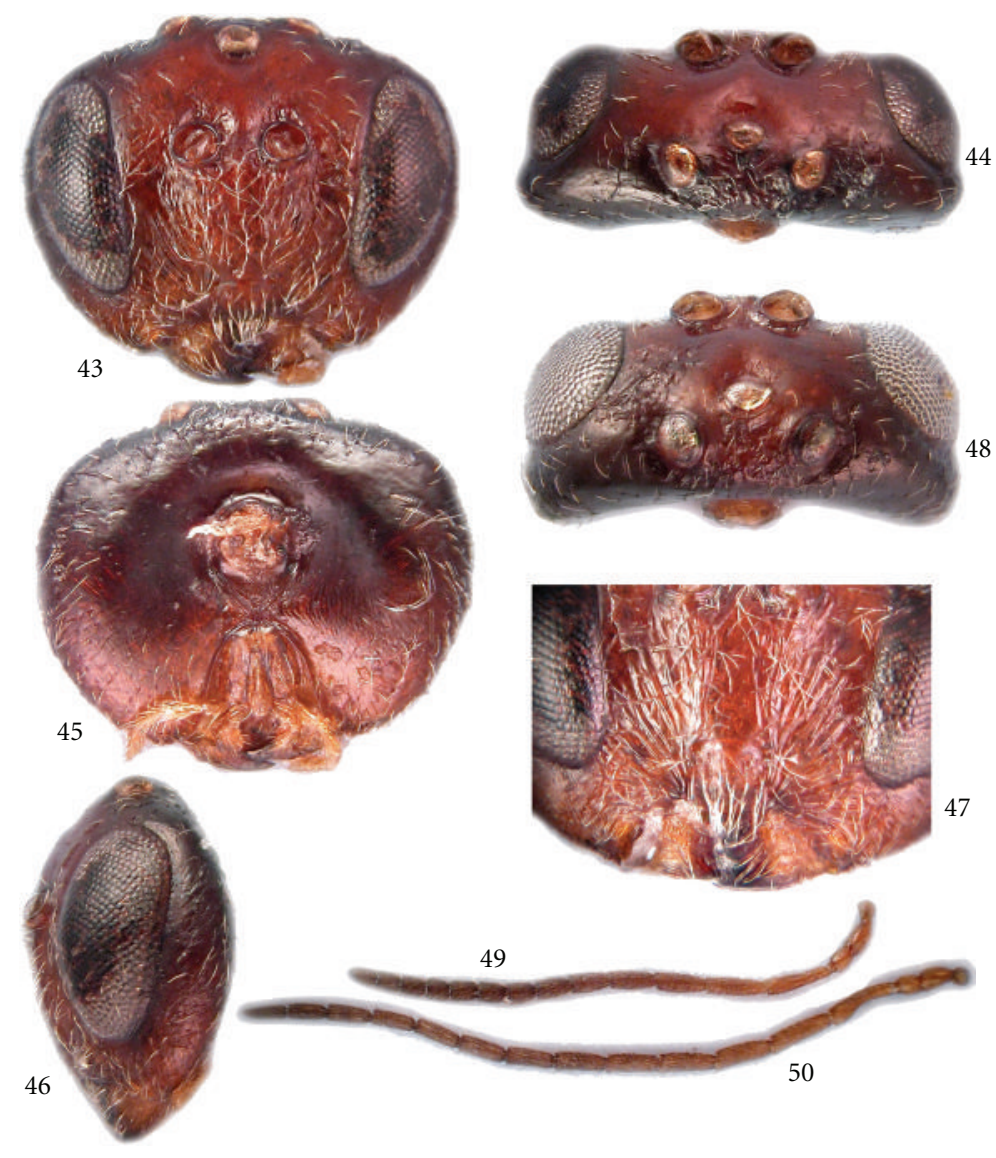

Figure 7: Drycosmus carlesiae, new species. (43-47) Head, female: (43) anterior view; (44) dorsal view; (45) posterior view; (46) lateral view; (47) lower face and clypeus, anterior view. (48) Head, male, dorsal view. (49-50) Antenna: (49) female; (50) male.

\subsubsection{Description}

Female. Head uniformly dark brown to chestnut brown; with slightly lighter clypeus and lower face; labial and maxilly palps yellow; antenna brown, especially flagellomeres much darker dorsally; mesosoma chestnut brown to brown, tegula always lighter; mesoscutellum dark brown to black; legs uniformly yellow, except dark brown hind tibiae and tarsi; metasoma dark brown, usually dorsally darker than laterally.

Head alutaceous, with sparse white setae, more dense on lower face, 1.9x broader than long from above; $1.1 \mathrm{x}$ broader than high in anterior view and slightly broader than mesosoma. Gena alutaceous, not broadened behind eye, 2.6x narrower than cross-diameter of eye, invisible in anterior view. Malar space alutaceous, with striae radiating from clypeus and reaching eye; height of eye $3.5 x$ longer as length of malar space; compound eyes slightly converging ventrally. POL 1.8x longer than OOL; OOL 1.1x longer than diameter of lateral ocellus, $1.3 x$ longer than LOL; ocelli ovate, all three equal in length. Transfacial distance as long as height of eye and $1.4 \mathrm{x}$ longer than height of lower face (distance between antennal rim and ventral margin of clypeus); diameter of antennal torulus $1.4 \mathrm{x}$ longer than distance between them, distance between torulus and eye margin equal to diameter of torulus. Lower face with numerous delicate striae radiating from clypeus and extending to lower level of antennal rim and into area between eye and torulus; median area slightly elevated. Clypeus rectangular, flat, slightly higher than broad, alutaceous, with deep anterior tentorial pits, distinct epistomal sulcus and clypeo-pleurostomal line; ventrally rounded and not incised medially. Frons alutaceous; vertex and occiput alutaceous with some delicate short irregular striae; interocellar area delicately coriaceous, elevated. Postgena smooth, shiny, postocciput around occipital foramen impressed, smooth, shiny with parallel interrupted delicate numerous striae; posterior tentorial pits large, deep, elongate; lower half of postgenal bridge narrowed to a stripe; occipital foramen slightly higher or as high as height of postgenal bridge, around $1.3 \mathrm{x}$ shorter than height of oral foramen. Antenna with 12 distinct flagellomeres (or 13 , indistinct suture between F12 and F13 visible in some individuals), longer than head + mesosoma; pedicel $1.3 \mathrm{x}$ longer than broad; scape + pedicel 1.2x longer than F1; F1 1.3x longer than F2, F2 only slightly longer than F3, F3 = F4, F5-F11 shorter than F4 and nearly equal in length; fused F12 + F13 1.9x longer than F11; placodeal sensilla on F1-F12, in numerous rows.

Mesosoma longer than high in lateral view. Pronotum smooth, shiny; with few white setae and with irregular delicate wrinkles laterally, emarginate along lateral edge, 


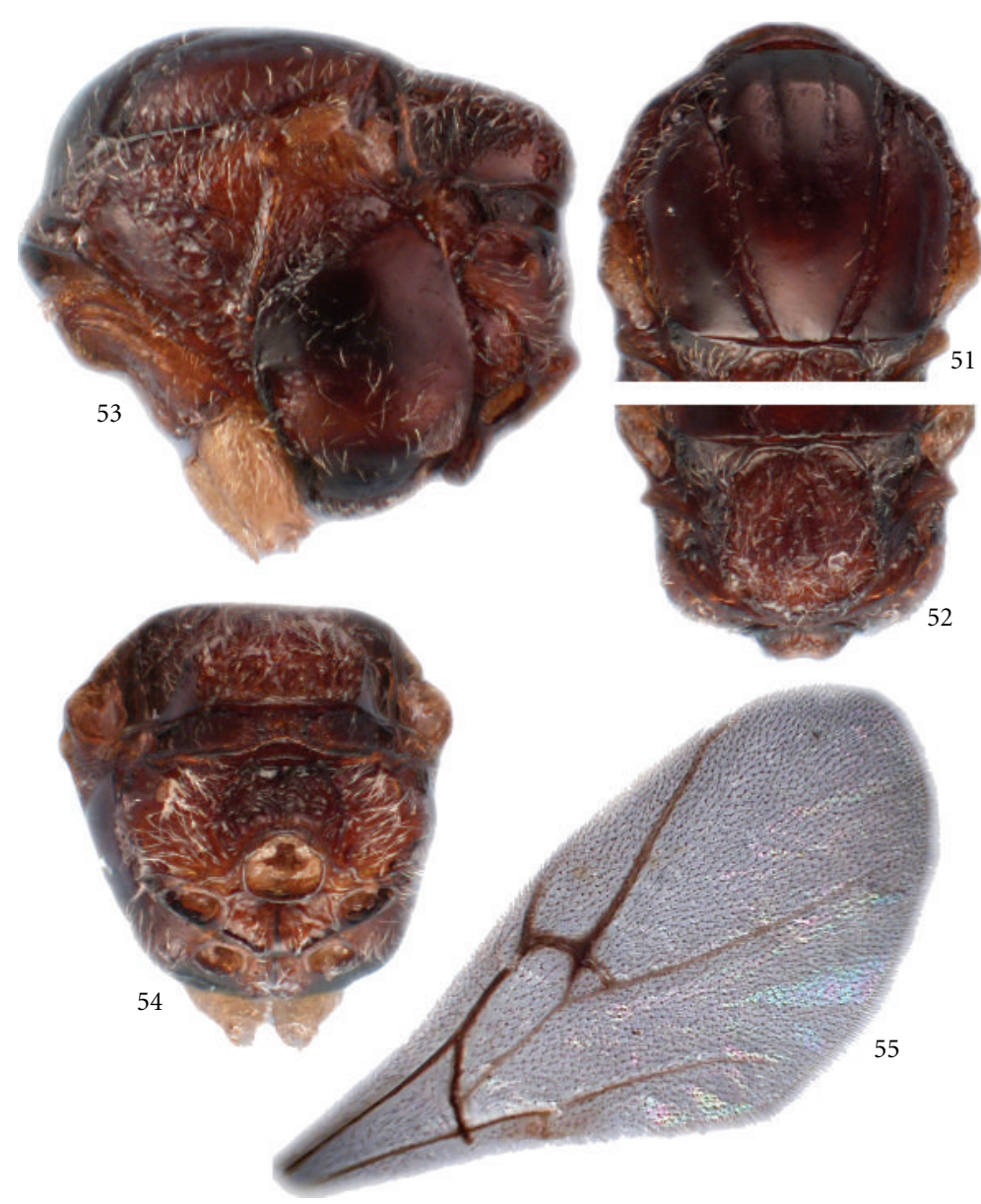

FIGURE 8: Drycosmus carlesiae, new species, female: (51) mesoscutum, dorsal view; (52) mesoscutellum, dorsal view; (53) mesosoma, lateral view; (54) metascutellum and propodeum, posterodorsal view; (55) forewing.

followed by deep longitudinal invagination. Anterior rim of pronotum narrow, emarginate; propleuron alutaceous, with few setae, strongly concave in mediocentral part. Mesoscutum smooth, shiny; nearly as long as broad (width measured across basis of tegulae); notauli complete, deeply impressed for full length; median mesoscutal line absent; anterior parallel and parapsidal lines not impressed, hardly traceable; parascutal carina broad, anteriorly reaching notauli. Transscutal articulation deep, distinct. Mesoscutellum only slightly longer than broad, rectangular, with parallel sides; shorter than mesoscutum, uniformly coriaceous, overhanging metanotum; scutellar foveae transverse ovate, with shiny bottom and few wrinkles on it, divided by central narrow elevated area (in some individuals foveae indistinctly separated by central elevated area and form a transverse impression along anterior margin of mesoscutellum). Mesopleuron smooth, shiny, with few white setae and irregular delicate wrinkles which forming a transverse line bent in the middle and going across entire width of mesopleuron, as well as in dorsoposterior one quarter of mesopleuron; mesopleural triangle shiny, with few white setae and some delicate irregular short wrinkles. Metapleural sulcus reaching mesopleuron slightly above half height; preaxilla delicately coriaceous, shiny; dorsal and lateral axillar areas shiny, smooth, with few setae; axillar carina broad, with longitudinal striae; subaxillular bar narrow, smooth, shiny, in most posterior end slightly higher than height of metanotal trough. Metascutellum uniformly coriaceous, slightly higher than height of smooth, shiny ventral impressed area; metanotal trough smooth, shiny, without setae. Lateral propodeal carinae distinct, lyre-shaped, bent outwards at mid height, central propodeal area smooth, shiny, with numerous delicate irregular wrinkles; lateral propodeal area coriaceous, with dense white setae; nucha very short, with delicate longitudinal sulci dorsolaterally and laterally.

Forewing as long or slightly longer than body, with distinct brown veins, margin with long dense cilia; radial cell $4.05 \mathrm{x}$ longer than broad, R1 and Rs reaching wing margin; areolet large, triangular, well-delimited by distinct veins; Rs $+\mathrm{M}$ well-pigmented, reaching basalis in the lower third.

Tarsal claws simple, without basal lobe. Metasoma nearly as long as length of head + mesosoma, longer than high in lateral view, smooth, shiny, without setae; only 2nd metasomal tergites laterally with very few white setae; 2 nd tergite extending to $1 / 3$ length of metasoma; prominent part of ventral spine of hypopygium short, nearly $2.0 \mathrm{x}$ longer 


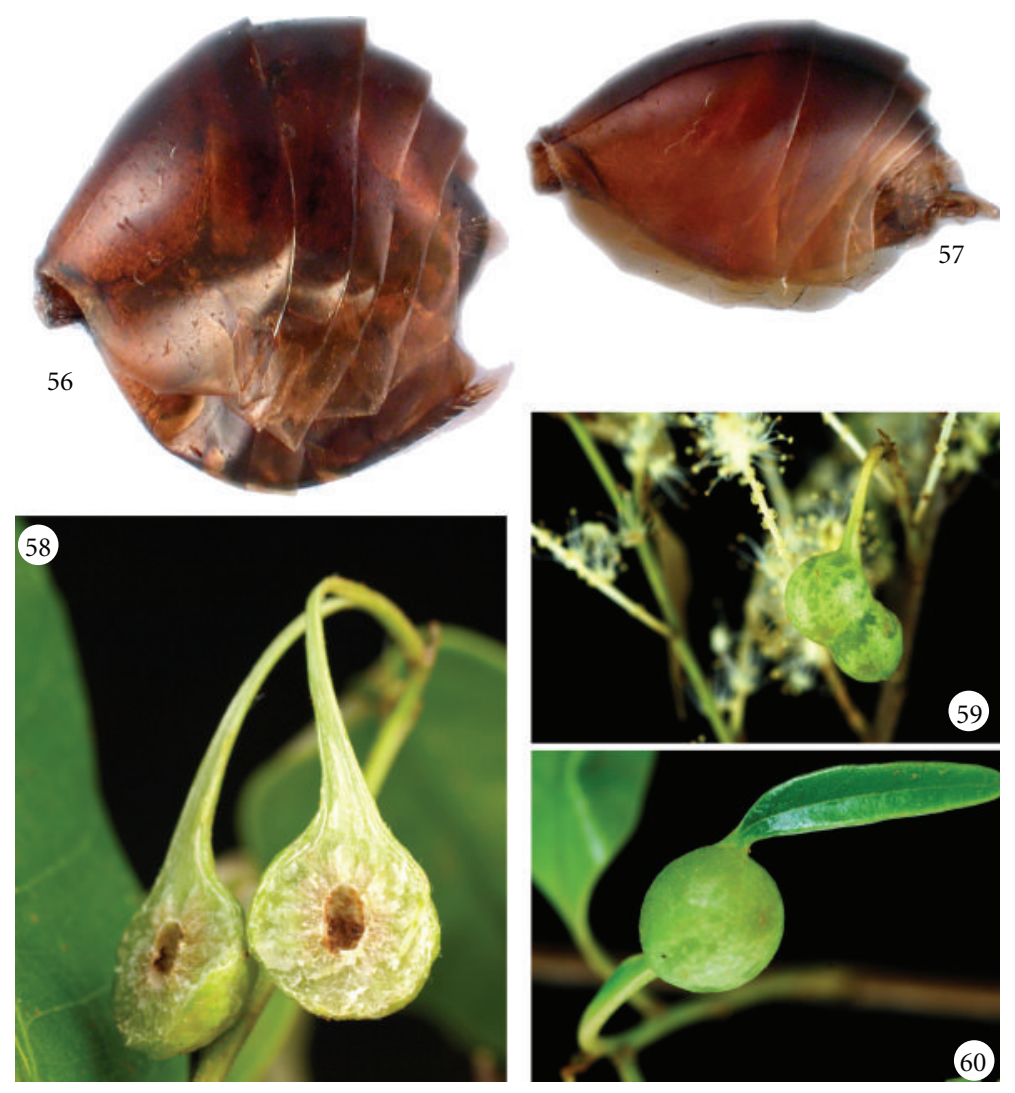

Figure 9: Drycosmus carlesiae, new species. (56-57) Metasoma, lateral view: (56) female; (57) male. (58-60) Galls ((59, 60) by Chang-Fu $\mathrm{Wu}$; (58) by Chang-Ti Tang).

than broad in ventral view, with long white setae, extending beyond apex of spine but never forming a tuft. Body length $2.1-2.4 \mathrm{~mm}(n=7)$.

Male. The colour pattern of the body the same as in female but usually much darker to black. Similar to female but compound eyes bigger and thus frons and lower face narrower than in female; also ocelli much bigger. Antenna longer than body, with 13 flagellomeres, proximal half of F1 broader than basal half, curved and excavated; scape, pedicel and F1 yellow, much lighter than all subsequent flagellomeres; pedicel extremely long, nearly as long as length of scape. Body length $1.8-2.1 \mathrm{~mm}(n=6)$.

2.2.5. Gall (Figure 6(40, 41, 42)). The gall closely resembles that of herein described $D$. pentagonalis. However, galls are forming on buds, catkins, and young leaves. The gall has only three distinct longitudinal ribs, thus has a triangular cross-section; $4.5-7.0 \mathrm{~mm}$ long, $1.2-1.9 \mathrm{~mm}$ width in crosssection; the stalk is usually much shorter than in $D$. pentagonalis, only 2-3 mm long. The gall stays green when mature, the central part of the gall is yellowish brown in between green longitudinal ribs, showing the position of the inner larval chamber. The body of the gall only slightly broader in diameter as the stalk which with it is attached to the plant.
2.2.6. Biology. Only the sexual generation is known, inducing galls on Castanopsis carlesii. Galls appear on the tree from early March, mature in mid-March, adults emerged in late March-April.

\subsubsection{Distribution. Taiwan, Taitung County (Figure 13).}

\subsection{Dryocosmus carlesiae Tang \& Melika, New Species Figures 7,8 , and 9}

\subsubsection{Type Material}

Holotype Female. TAIWAN, Taitung County, Daren Forest Station, Daren Township, ex Castanopsis carlesii, leg. ChangTi Tang, 28.III.2010. adult em. 12.IV.2010. PARATYPES: 13 females and 9 males: 3 female and 3 male paratypes with the same labels as the holotype; female paratype: TAIWAN, Taitung County, Daren Forest Station, Daren Township, ex C. carlesii, leg. Chang-Ti Tang, 14.III.2010. adult em. 06.IV.2010; 1 female paratype: TAIWAN, Taitung County, Daren Forest Station, Daren Township, ex C. carlesii, leg. Chang-Ti Tang, 14.III.2010. adult dissected from gall on 02.IV.2010; 1 male paratype: TAIWAN, Taitung County, Daren Forest Station, Daren Township, ex C. carlesii, leg. Chang-Ti Tang, 14.III.2010. adult dissected from gall on 08.IV.2010; 2 female paratypes: TAIWAN, Taitung County, 


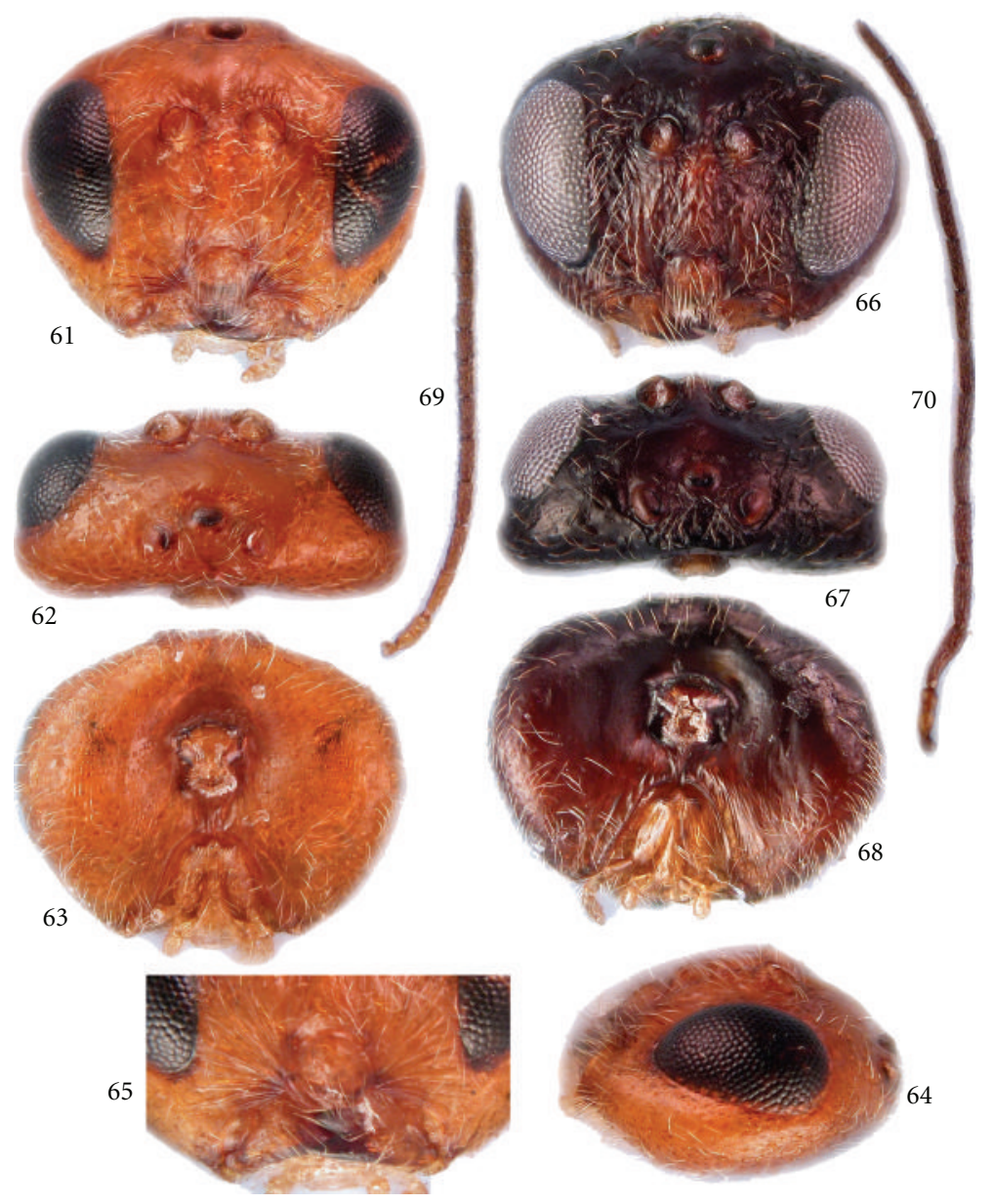

FIGURe 10: Drycosmus testisimilis, new species. (61-65) Head, female: (61) anterior view; (62) dorsal view; (63) posterior view; (64) lateral view; (65) lower face and clypeus, anterior view. (66-68) Head, male: (66) anterior view; (67) dorsal view; (68) posterior view. (69-70) Antenna: (69) female; (70) male.

Daren Forest Station, Daren Township, ex C. carlesii, leg. Chang-Ti Tang, 14.III.2010. adult dissected from gall on 12.IV.2010; 1 male paratype: TAIWAN, Pingtung County, LiLung Mountain, Shrtz Township, ex C. carlesii, leg. Chang-Ti Tang, 27.III.2010. adult em. 12.IV.2010; 1 female paratype: TAIWAN, Pingtung County, Li-Lung Mountain, Shrtz Township, ex C. carlesii, leg. Chang-Ti Tang, 27.III.2010. adult em. 16.IV.2010; 1 male and 3 female paratypes: TAIWAN, Pingtung County, Li-Lung Mountain, Shrtz Township, ex C. carlesii, leg. Chang-Ti Tang, 27.III.2010. adults dissected from galls on 14.IV.2010; 2 female and 2 male paratypes: TAIWAN, Taitung County, Daren Forest Station, Daren Township, ex C. carlesii, leg. Chang-Ti Tang, 28.III.2010. adult em. 08.IV.2010; 1 male paratype: TAIWAN, Taitung County, Daren Forest Station, Daren Township, ex C. carlesii, leg. Chang-Ti Tang, 28.III.2010. adult dissected from gall on 14.IV.2010. The holotype female, and 3 female and 2 male paratypes are deposited in NMNS, 4 female and 3 male paratypes in PDL, 1 female and 1 male in USNM, and 5 female and 3 male paratypes in NCHU.

2.3.2. Etymology. The species named after the host plant, Castanopsis carlesii.
2.3.3. Diagnosis. Most closely related to D. testisimilis; however, in $D$. carlesiae females the head is darker, POL longer than OOL, OOL 1.7x longer than the diameter of the lateral ocellus, $2.2 \mathrm{x}$ longer than LOL; in males OOL $1.2 \mathrm{x}$ longer than the length of the lateral ocellus, the interocellar area alutaceous, like the frons, the scape + pedicel is equal in length to F1, F3 shorter than F2. In D. testisimilis females the head is much lighter, yellowish brown, POL shorter than OOL, OOL 3.0x longer than the diameter of the lateral ocellus, $2.7 \mathrm{x}$ longer than LOL; in males OOL 1.6x longer than the length of the lateral ocellus, the interocellar area coriaceous, with more dull sculpture than on the frons, the scape + pedicel is shorter than the length of F1, F3 $=$ F2 .

\subsubsection{Description}

Female. Head and antennae brown to light brown; posteriorly, especially postocciput, postgena and postgenal bridge usually darker; labial and maxilly palps yellow to dirty yellow; compound eyes black; mesoscutum, mesopleuron, metapleuron and propodeum dark brown, while pronotum, mesoscutellum always lighter; legs uniformly yellow, except 

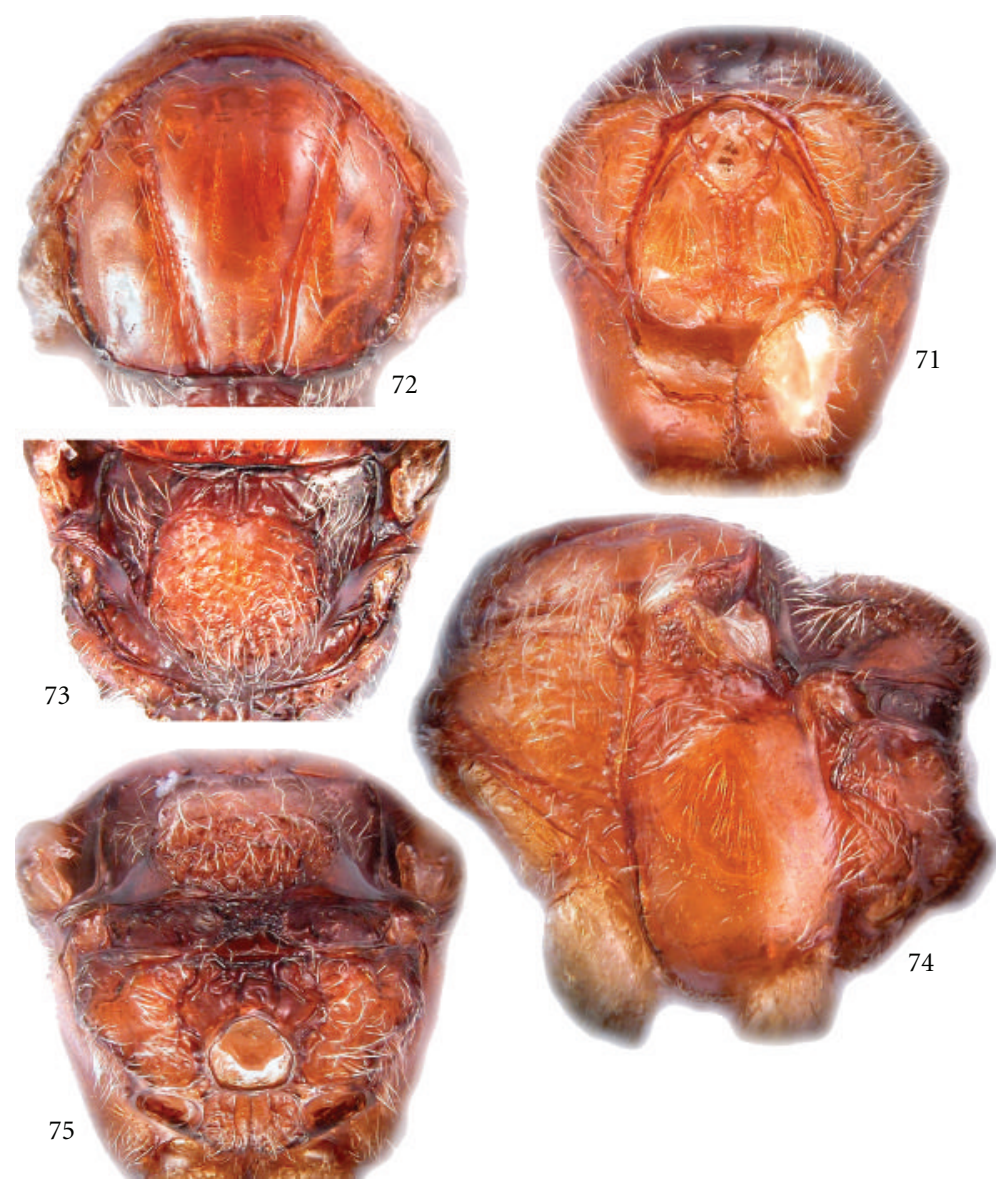

Figure 11: Drycosmus testisimilis, new species, female: (71) pronotum and propleura, anterior view; (72) mesoscutum, dorsal view; (73) mesoscutellum, dorsal view; (74) mesosoma, lateral view; (75) metascutellum and propodeum, posterodorsal view.

darker tarsal claws and hind tibiae; metasoma brown, dorsally usually darker.

Head alutaceous, with sparse white setae, more dense on lower face, shiny; $2.35 \mathrm{x}$ broader than long from above; $1.3 \mathrm{x}$ broader than high in anterior view and slightly broader than mesosoma. Gena alutaceous, shiny, not or very slightly broadened behind eye, 2.0x narrower than cross-diameter of eye, invisible in anterior view. Malar space alutaceous, with striae radiating from clypeus and reaching eye; height of eye $3.5 x$ longer than length of malar space. Compound eyes converging ventrally. POL $1.35 \mathrm{x}$ longer than $\mathrm{OOL}$; OOL $1.7 \mathrm{x}$ longer than diameter of lateral ocellus, $1.8 \mathrm{x}$ longer than LOL; ocelli ovate, all three equal in length. Transfacial distance $1.2 \mathrm{x}$ longer than height of eye and $1.4 \mathrm{x}$ longer than height of lower face (distance between antennal rim and ventral margin of clypeus); diameter of antennal torulus nearly equal to distance between them, distance between torulus and eye margin $1.4 \mathrm{x}$ longer than diameter of torulus. Lower face alutaceous, with numerous delicate striae radiating from clypeus and extending to lower level of antennal rim, with elevated smooth, shiny median area. Clypeus rectangular, flat, slightly broader than high, smooth, shiny, with small anterior tentorial pits, indistinct epistomal sulcus and clypeo-pleurostomal line; ventrally rounded, narrowly emarginate and not incised medially.
Frons, vertex and occiput smooth, shiny; interocellar area delicately coriaceous, slightly elevated. Postgena smooth, shiny, postocciput around occipital foramen impressed, smooth, shiny; posterior tentorial pits small, rounded; postgenal bridge short, triangular-like, continuously narrowed down to emarginate hypostomal carina; occipital foramen nearly $1.5 \mathrm{x}$ higher than height of postgenal bridge, around $1.4 \mathrm{x}$ shorter than height of oral foramen. Antenna with 12 or 13 flagellomeres (in some individuals suture between F12 and F13 indistinct), longer than head + mesosoma; pedicel $1.4 \mathrm{x}$ longer than broad, F1 slightly shorter than scape + pedicel, 1.15x longer than F2, F2 1.3x longer than F3, F3 slightly longer than F4, F5-F11 shorter than F4 and nearly equal in length; fused F12 + F13 2.0x longer than F11 (if suture between F12 and F13 well-developed, than F13 slightly longer than F12); placodeal sensilla on F1-F13, in numerous rows.

Mesosoma only very slightly longer or nearly as long as high in lateral view, not compressed dorsoventrally. Pronotum smooth, shiny; with few white setae and with irregular delicate wrinkles laterally, emarginate along lateral edge, followed by deep longitudinal invagination. Anterior rim of pronotum narrow, emarginate; propleuron alutaceous, with few setae, strongly concave in mediocentral part. Mesoscutum smooth, shiny; nearly as long as broad 


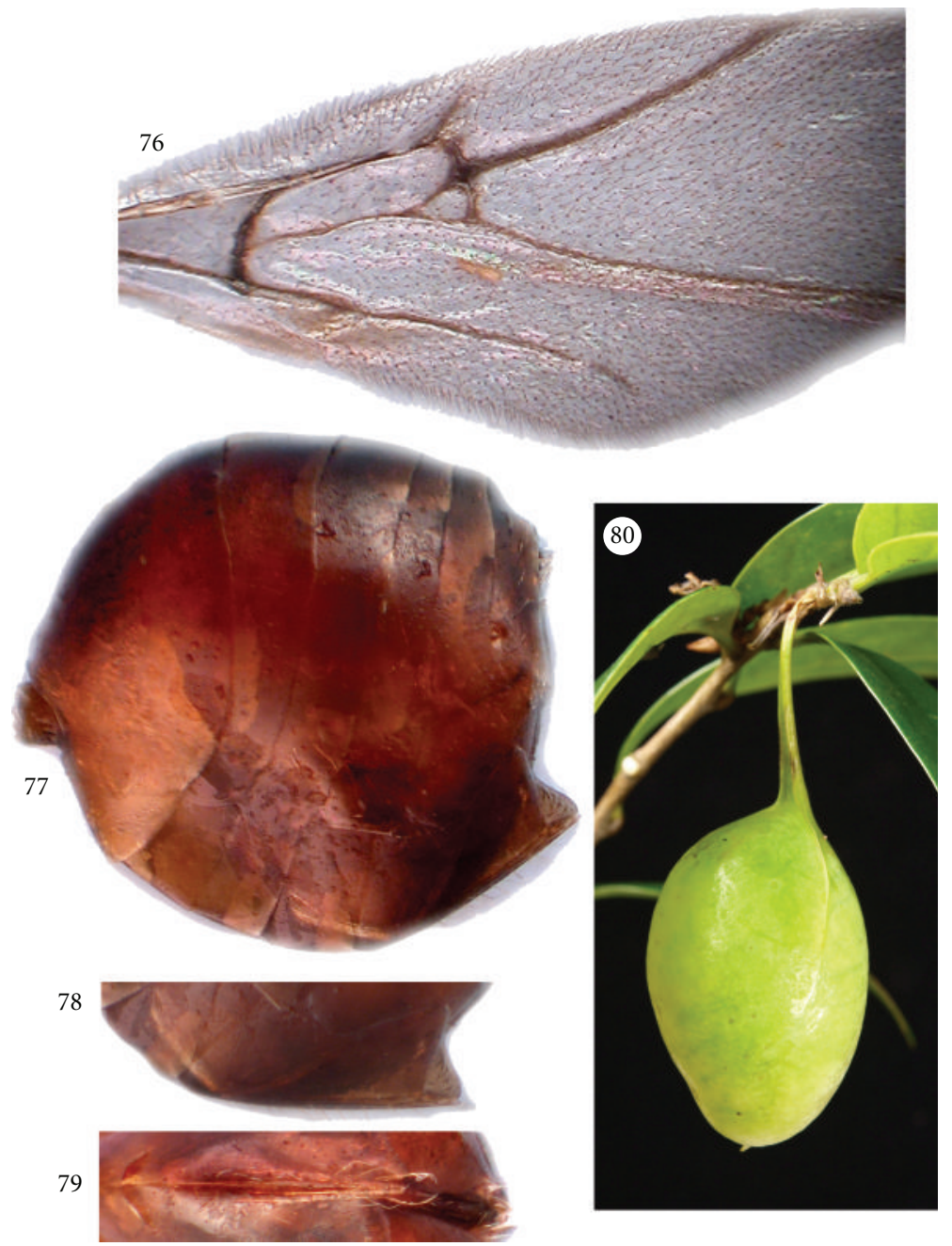

Figure 12: Drycosmus testisimilis, new species, female: (76) forewing; (77) metasoma, lateral view. (78-79) Ventral spine of hypopygium: (78) lateral view; (79) ventral view. (80) Gall (photos by Chang-Ti Tang).

(width measured across basis of tegulae); notauli complete, deeply impressed for full length; median mesoscutal line absent; anterior parallel impressed, distinct, extending to $1 / 3$ of mesoscutum length; parapsidal lines not impressed, hardly traceable; parascutal carina broad, anteriorly reaching notauli. Transscutal articulation deep, distinct. Mesoscutellum only slightly longer than broad, rectangular, with parallel sides; shorter than mesoscutum, uniformly coriaceous, overhanging metanotum; scutellar foveae transversely ovate, with shiny bottom and few wrinkles on it, divided by central narrow elevated area. Mesopleuron and speculum uniformly smooth and shiny, without transversely orientated striae at mid height; mesopleural triangle shiny, with few white setae and some delicate irregular short wrinkles. Metapleural sulcus reaching mesopleuron slightly above half height; preaxilla delicately coriaceous, shiny; dorsal and lateral axillar areas shiny, smooth, with few setae; axillar carina broad, with longitudinal striae; subaxillular bar narrow, smooth, shiny, in most posterior end slightly higher than height of metanotal trough. Metascutellum uniformly coriaceous, slightly higher than height of smooth, shiny ventral impressed area; metanotal trough smooth, shiny, without setae. Lateral propodeal carinae distinct, lyre-shaped, bent outwards at mid height, central propodeal area smooth, shiny, with numerous delicate irregular wrinkles; lateral propodeal area coriaceous, with dense white setae; nucha very short, with delicate longitudinal sulci dorsolaterally and laterally.

Forewing as long or slightly longer than body, with distinct brown veins, margin with long dense cilia; radial cell 4.0x longer than broad, R1 and Rs reaching wing margin; areolet large, triangular, well-delimited by distinct veins; Rs $+\mathrm{M}$ well-pigmented, reaching basalis in the lower third.

Tarsal claws simple, without basal lobe. Metasoma slightly shorter than head + mesosoma, slightly higher than long in lateral view, smooth, shiny, without setae; only 2 nd metasomal tergites laterally with very few white setae; 2 nd tergite extending to $1 / 3$ length of metasoma; prominent part of ventral spine of hypopygium short, nearly $2.0 \mathrm{x}$ or less longer than broad in ventral view, with long white setae, extending beyond apex of spine but never forming a tuft. Body length 2.7-3.1 $\mathrm{mm}(n=5)$. 
Table 1: Key to the Dryocosmus Species of Tiwan.

(1) - Female

- Male

- Mesosoma distinctly longer than high in lateral view, compressed dorsoventrally; mesopleuron with distinct transversely orientated numerous delicate striae in mid height, forming distinct bent across entire length of mesopleuron (Figures 2(12), 5(34)); posterior tentorial pits large, deep, elongate; occipital foramen very slightly higher or equal to height of postgenal bridge, lower half of which narrow, stripe-like (Figures 1(3) and 4(25))

(2)

- Mesosoma nearly as long as high in lateral view, not compressed dorsoventrally; mesopleuron and speculum uniformly smooth and shiny, without transversely orientated striae at mid height (Figures 8(53) and 11(74)); posterior tentorial pits small, rounded; occipital foramen nearly $1.5 \mathrm{x}$ higher than height of postgenal bridge which short, triangular-like, continuously narrowed down towards hypostomal carina (Figures 7(45), and $10(63))$

- POL 1.4x longer than OOL (Figure 1(2)); scape + pedicel longer than F1 (Figure 1(7)); scutellar foveae transverse ovate, with shiny bottom and few wrinkles on it, divided by central elevated area which only slightly pentagonalis narrower than width of fovea (Figure 2(11))

(3)

- POL 1.8x longer than OOL (Figure 4(24)); scape + pedicel only 1.2x longer than F1 (Figure 4(29)) scutellar

foveae transverse ovate, with shiny bottom and few wrinkles on it, divided by central narrow elevated area (Figure 5(33))

- Height of eye 3.5x longer than length of malar space; POL longer than OOL; OOL 1.7x longer than diameter of lateral ocellus, 1.8x longer than LOL (Figures 7(43)-(44))

(4)

- Height of eye 2.25x longer than length of malar space; POL shorter than OOL; OOL 3.0x longer than diameter of lateral ocellus, 2.7x longer than LOL (Figures 10(61)-(62))

- POL at least 3.0x longer than OOL; ocelli large, at least 3.0x larger than length of OOL (Figures 1(6)

(5) and 4(27))

- POL slightly longer than OOL; ocelli smaller, length nearly equal to length of OOL (Figures 7(48) and 10(67))

triangularis

- Height of compound eye 8.1x higher than length of malar space and 1.2x higher than length of transfacial distance (Figure 1(5)); pedicel definitely shorter than scape (Figure 1(8))

- Height of compound eye $8.7 x$ higher than length of malar space and 1.4x higher than length of transfacial distance (Figure 4(26)); pedicel nearly as long as scape (Figure 4(30))

- OOL 1.6x longer than length of lateral ocellus; interocellar area alutaceous, like frons (Figure 7(48)); scape + pedicel equal in length to F1, F3 shorter than F2 (Figure 7(50))

testisimilis

- OOL 1.8x longer than length of lateral ocellus, interocellar area coriaceous, with more dull sculpture than frons (Figure 10(70)); scape + pedicel shorter than length of F1, F2 = F3 (Figure 10(67))

testisimilis

Male. Lower face brown, while rest of head dark brown to black; mesosoma, dark brown to black, except always light brown pronotum (in some specimens head and mesosoma entirely brown); legs yellow; metasoma yellowish brown, dorsally and dorsolaterally much darker. Similar to female but compound eyes bigger and thus frons and lower face narrower than in female; also ocelli much bigger. Antenna longer than body, with 13 flagellomeres, proximal 1/3 of F1 broader than basal half, curved and excavated. Body length $2.1-2.4 \mathrm{~mm}(n=4)$.

2.3.5. Gall (Figure 9(58, 59, 60)). Galls develop from leaf buds or on leaves. The body of the gall located on a long, thin stalk, 10-20 mm long, growing out from the bud or forming within the leaf petiole. The body of the gall rounded, spherical, $7.0-8.3 \mathrm{~mm}$ in diameter. The gall is green with the surface smooth, shiny, mottled with some whitish irregular spots. The parenchyma of the gall is green, juicy, with a centrally located larval chamber, $3.0-3.5 \mathrm{~mm}$ in length and diameter usually half of the length. Unilocular.

2.3.6. Biology. Only the sexual generation is known from galls on Castanopsis carlesii (Hemsl.). Galls appear on the tree from early March, mature by mid- to late March, adults emerged in April. The asexual generation is not known yet.

2.3.7. Distribution. Taiwan, Taitung and Pingtung Counties (Figure 13).

\subsection{Dryocosmus testisimilis Tang \& Melika, New Species Figures 10, 11, and 12}

\subsubsection{Type Material}

Holotype Female. TAIWAN, Taoyuan County, Fushing Township, ex Castanopsis uraiana, leg. Chang-Ti Tang, 20.III.2010. adult dissected from gall on 02.IV.2010. PARATYPES: 4 females and 1 male: 1 female paratype with the same label as the holotype; 2 female paratypes: TAIWAN, Taoyuan County, Fushing Township, ex C. uraiana, leg. Chang-Ti Tang, 20.III.2010. adult dissected from gall on 12.IV.2010; 1 female paratype: TAIWAN, Taoyuan County, Fushing Township, ex C. uraiana, leg. Chang-Ti Tang, 08.IV.2010. adult dissected from gall on 11.V.2010; 1 male paratype: TAIWAN, Taoyuan County, Fushing Township, ex C. uraiana, leg. Chang-Ti Tang, 08.IV.2010. adult dissected 


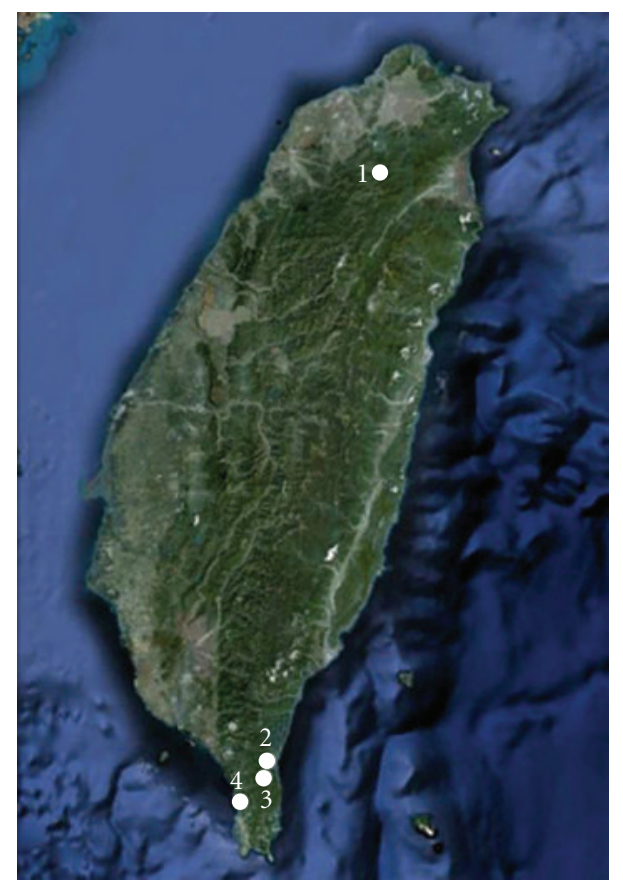

Figure 13: Current distribution of Dryocosmus species in Taiwan indicate by numbers (figure from http://www.google.com/earth/): (1) D. testisimilis; (2) D. triangularis; (3) D. pentagonalis; $(3,4)$ D. carlesiae.

from gall on 02.V.2010. The holotype female, 1 female paratype are deposited in NMNS, 2 female and 1 male paratypes in PDL, and 1 female paratype in NCHU.

2.4.2. Etymology. The species named after the shape of the gall which is reminiscent of mammalian testicles.

2.4.3. Diagnosis. See diagnosis to D. carlesiae and the key to species below.

\subsubsection{Description}

Female. The colour pattern as in the previous species, D. carlesiae, although the entire body slightly lighter. Head alutaceous, smooth with sparse white setae, more dense on lower face, $2.2 \mathrm{x}$ broader than long from above; $1.23 \mathrm{x}$ broader than high in anterior view and slightly broader than mesosoma. Gena alutaceous, not or very slightly broadened behind eye, $1.8 \mathrm{x}$ narrower than cross-diameter of eye, invisible in anterior view. Malar space alutaceous, with striae radiating from clypeus and reaching inner margin of eye; height of eye $2.25 x$ longer than length of malar space. Compound eyes slightly converging ventrally. POL $0.9 x$ longer than OOL; OOL 3.0x longer than diameter of lateral ocellus, $2.7 \mathrm{x}$ longer than LOL; ocelli ovate, all three equal in length. Transfacial distance $1.3 \mathrm{x}$ longer than height of eye and $1.7 \mathrm{x}$ longer than height of lower face (distance between antennal rim and ventral margin of clypeus); diameter of antennal torulus only slightly longer than distance between toruli, distance between torulus and eye margin equal to diameter of torulus. Lower face alutaceous, with striae radiating from clypeus and extending half height of lower face, not reaching to antennal rims. Clypeus rectangular, flat, slightly broader than high, smooth, shiny, with shallow anterior tentorial pits, distinct epistomal sulcus and clypeo-pleurostomal line; ventrally rounded and not incised medially. Frons, vertex, occiput and interocellar area smooth, shiny; postgena smooth, shiny, postocciput around occipital foramen impressed, smooth, shiny; posterior tentorial pits small, rounded; postgenal bridge short, triangular-like, continuously narrowed down to emarginate hypostomal carina; occipital foramen nearly $1.5 \mathrm{x}$ higher than height of postgenal bridge, around $1.5 \mathrm{x}$ shorter than height of oral foramen. Antenna with 12 distinct flagellomeres (or 13, indistinct suture between F13 and F12 visible in some individuals), longer than head + mesosoma; pedicel as long as broad, F1 slightly shorter than scape + pedicel and equal to F2, F2 only slightly longer than F3, F3 = F4, F5-F11 shorter than F4 and nearly equal in length; fused F12 + F13 1.8x longer than F11; placodeal sensilla on F1-F12, in numerous rows.

Mesosoma only very slightly longer or nearly as long as high in lateral view, not compressed dorsoventrally. Pronotum smooth, shiny; with few white setae and with irregular delicate wrinkles laterally, emarginate along lateral edge, followed by deep longitudinal invagination. Anterior rim of pronotum narrow, emarginate; propleuron alutaceous, with few setae, strongly concave in mediocentral part. Mesoscutum smooth, shiny; nearly as long as broad (width measured across basis of tegulae); notauli complete, deeply impressed for full length; median mesoscutal line absent; anterior parallel and parapsidal lines not impressed, hardly traceable; parascutal carina broad, anteriorly reaching notauli. Transscutal articulation deep, distinct. Mesoscutellum slightly longer than broad, rectangular, with parallel sides; shorter than mesoscutum, uniformly coriaceous, overhanging metanotum; scutellar foveae transverse ovate, with shiny bottom and few wrinkles on it, divided by central narrow sharp carina. Mesopleuron and speculum uniformly smooth and shiny, without transversely orientated striae at mid height; mesopleural triangle shiny, with few white setae and some delicate irregular short wrinkles. Metapleural sulcus reaching mesopleuron slightly above half height; preaxilla delicately coriaceous, shiny; dorsal and lateral axillar areas shiny, smooth, with few setae; axillar carina broad, with longitudinal striae; subaxillular bar narrow, smooth, shiny, in most posterior end slightly higher than height of metanotal trough. Metascutellum uniformly coriaceous, slightly higher than height of smooth, shiny ventral impressed area; metanotal trough smooth, shiny, without setae. Lateral propodeal carinae distinct, lyre-shaped, bent outwards at mid height, central propodeal area smooth, shiny, with numerous delicate irregular wrinkles; lateral propodeal area coriaceous, with dense white setae; nucha very short, with delicate longitudinal sulci dorsolaterally and laterally.

Forewing as long or slightly longer than body, with distinct brown veins, margin with long dense cilia; radial cell 4.0x longer than broad, R1 and Rs reaching wing margin; areolet large, triangular, well-delimited by distinct veins; Rs $+\mathrm{M}$ well-pigmented, reaching basalis in the lower third. 
Tarsal claws simple, without basal lobe. Metasoma slightly shorter than head + mesosoma, slightly longer than high in lateral view, smooth, shiny, without setae; only 2 nd metasomal tergites laterally with very few white setae; 2 nd tergite extending to $1 / 3$ length of metasoma; prominent part of ventral spine of hypopygium short, nearly $2.0 \mathrm{x}$ longer than broad in ventral view, with long white setae, extending beyond apex of spine but never forming a tuft. Body length $3.1-3.3 \mathrm{~mm}(n=2)$.

Male. The colour pattern of the body the same as in female but usually much darker to black. The same as female but compound eyes bigger and thus frons and lower face narrower than in female; also ocelli much bigger. Antenna longer than body, with 13 flagellomeres, proximal half of F1 broader than basal half, curved and excavated. Body length $3.1 \mathrm{~mm}(n=1)$.

2.4.5. Galls (Figure 12(80)). The general appearance and the location of the gall closely resembles that of $D$. carlesiae (see the description of the gall above); however, the body of the gall is always elongated and larger than the gall of $D$. carlesiae, with $22-31 \mathrm{~mm}$ in length and $12-21 \mathrm{~mm}$ in diameter. The parenchyma of the gall is green, juicy, with many larval chambers gather centrally. Each larval chamber has 2.5$3.0 \mathrm{~mm}$ in length and $1.7-2.0 \mathrm{~mm}$ in diameter. Multilocular. The length of the gall body usually encompasses around $2 / 3$ of the entire length of the gall, including the length of the stalk.

2.4.6. Biology. Only the sexual generation is known from galls on Lithocarpus uraianus (Hayata) Hayata (= Castanopsis uraiana (Hayata) (synonym in [7]). Mature galls were collected in mid- and late March, adults emerged in April and May.

\subsubsection{Distribution. Taiwan, Taoyuan County (Figure 13).}

\section{Discussion}

Currently, 23 species are known to be valid in the Holarctic genus Dryocosmus Giraud, although previous work placed some Nearctic species $[22,23]$ and four Eastern Palaearctic species [24] in Dryocosmus erroneously. Most Dryocosmus species are known to have alternating sexual and asexual generations. The six Western Palaearctic species induce galls exclusively on section Cerris oaks, while all but three of the Nearctic species induce their galls on red oaks (section Lobatae); the Nearctic exceptions are the species D. castanopsidis (Beutenmueller) and D. rileypokei Morita and Buffington, which gall chinquapins, Chrysolepis Hjelmq. $[16,25]$, and D. assymetricus (Kinsey) which galls golden-cup oaks (section Protobalanus) [14]. The only previously known Eastern Palaearctic species, D. kuriphilus, galls chestnuts Castanea L. (details in $[2,26]$ ). Details of the lifecycles, gall morphology, biology, geographic distribution, and detailed morphological descriptions of the previously recognized species are given elsewhere $[11,13,16,27-30]$.
The genus Dryocosmus with its current classification and limits undoubtedly forms a polyphyletic group. Molecular data clearly show, for example, that the Nearctic species D. favus Beutenmüller, is phylogenetically distinct from Palaearctic Dryocosmus and is more closely allied to Andricus [31]. In addition, parsimony analysis of cytochrome oxidase I by Drown and Brown [32] clustered three Nearctic Dryocosmus species, D. quercuspalustris (Osten Sacken), D. quercusnotha (Osten Sacken), and D. imbricariae (Ashmead) (all associated with red oaks) with Andricus quercuslaniger (Ashmead). Therefore, in all possibility the remaining Nearctic Dryocosmus also either represent morphologically convergent lineages similarly distant from Palaearctic Dryocosmus, or a related lineage separated from Palaearctic relatives by a shift in host oak.

Recent analyses have indicated that even the Western Palaearctic Dryocosmus is polyphyletic. Dryocosmus kuriphilus appeared as sister to Chilaspis and other Dryocosmus species, and close to Plagiotrochus, in two single-gene analyses [31], while phylogenetic reconstructions based on morphology put it together with Chilaspis nitida (Giraud) [33]. The Dryocosmus species included by Stone et al. [12] fell into 3 distinct clades, with deep divergences between them: (i) D. caspiensis paired with Cerroneuroterus lanuginosus, (ii) D. cerriphilus was placed as sister to a clade of Aphelonyx species, and (iii) Chilaspis species (previously placed in Dryocosmus by Ács et al. [31]) formed a distinct clade, sister to Plagiotrochus, thus supporting the re-establishment the genus. Ongoing molecular analyses (J. A. Nicholls and G. N. Stone, unpublished data) with broader taxon sampling in Dryocosmus confirm these relationships and the polyphyly of Dryocosmus, and further suggest (i) that D. mayri is allied to D. caspiensis and (ii) that D. tavakoli and D. mikoi may form a subclade within the D. mayri-caspiensis complex. Preliminary molecular data for three of the four herein described species from Taiwan (D. pentagonalis, D. triangularis, and D. carlesiae) also indicate that these species cluster in a distinct clade with $D$. kuriphilus, well-distanced from all other Dryocosmus species. Hence, Palaearctic Dryocosmus (and by extension Holarctic Dryocosmus, with numerous dubiously positioned Nearctic species) is a polyphyletic genus, with at least three major groups_-kuriphilus and other East Asian species, mayri/caspiensis and related taxa, and cerriphilus. However, further DNA sequence analysis involving all known Holarctic Dryocosmus species is necessary to redefine "true" Dryocosmus, alongside detailed examination of morphological character states in each lineage. Such a revision of the Holarctic Dryocosmus is in progress, and once distinguishing characters are defined, several new genera can probably be erected to replace the current polyphyletic Dryocosmus.

\section{References}

[1] O. V. Kovalev, "Gall wasps (Hymenoptera, Cynipidae) from the south of the Soviet Far East," Entomologicheskoye Obozrenije, vol. 44, no. 1-2, pp. 46-73, 1965 (Russian), English translation in Entomological Review, vol. 44, pp. 25-38. 
[2] Y. Abe, G. Melika, and G. N. Stone, "The diversity and phylogeography of cynipid gallwasps (Hymenoptera: Cynipidae) of the oriental and eastern Palearctic regions, and their associated communities," Oriental Insects, vol. 41, pp. 169-212, 2007.

[3] G. Melika, J. Pujade-Villar, Y. Abe et al., "Palaearctic oak gallwasps galling oaks (Quercus) in the section Cerris: reappraisal of generic limits, with descriptions of new genera and species (Hymenoptera: Cynipidae: Cynipini)," Zootaxa, no. 2470, pp. 1-79, 2010.

[4] M. M. Yang, G. S. Tung et al., "The diversity of insect-induced galls on vascular plants in Taiwan: a preliminary report," General Technical Report NC-199, USDA Forestry Service North Central Forestry Experimental Station, 1998.

[5] S. Y. Yang, M. Y. Chen, and J. T. Yang, Plant Galls in Taiwan, Council of Agriculture, Taipei, Taiwan, 2000.

[6] C. T. Tang, G. Melika, M. M. Yang, J. Nicholls, G. Csóka, and G. N. Stone, "First record of an Andricus oak gallwasp from the Oriental region: a new species from Taiwan (Hymenoptera: Cynipidae: Cynipini)," Zootaxa, no. 2175, pp. 57-65, 2009.

[7] R. Govaerts and D. G. Frodin, World Checklist and Bibliography of Fagales, Royal Botanic Gardens, Kew, UK, 1998.

[8] F. Y. Lu, C. H. Ou, Y. C. Chen, Y. S. Chi, K. C. Lu, and Y. H. Tseng, Trees of Taiwan, vol. 2, Department of Forestry, National Chung Hsing University, Taichung, Taiwan, 2006.

[9] J. Yukawa and H. Masuda, Eds., Insect and Mite Galls of Japan in Colors, Zenkoku-Nouson-Kyoukai, Tokyo, Japan, 1996.

[10] J. J. Kieffer, "Les Cynipides," in Andre, Species d'Hymenoptera d'Europe et d'Algerie, vol. 2, pp. 273-496, 1904.

[11] K. W. Dalla Torre and J. J. Kieffer, Cynipidae, Das Tierreich, 24, Friedlander \& Sohn, Berlin, Germany, 1910.

[12] G. N. Stone, A. Hernandez-Lopez, J. A. Nicholls et al., "Extreme host plant conservatism during at least 20 million years of host plant pursuit by oak gallwasps," Evolution, vol. 63, no. 4, pp. 854-869, 2009.

[13] G. Melika, "Gall Wasps of Ukraine. Cynipidae," Vestnik Zoologii, Supplement, vol. 21, no. 1-2, pp. 1-644, 2006.

[14] A. C. Kinsey, "Studies of some new and described Cynipidae (Hymenoptera)," Indiana University Studies, vol. 9, no. 53, pp. 1-141, 1922.

[15] B. D. Burks, "Superfamily Cynipoidea," in Catalog of Hymenoptera in America North of Mexico. Symphyta and Apocrita (Parasitica), K. V. Krombein, P. D. Hurd Jr., D. R. Smith, and B. D. Burks, Eds., vol. 1, pp. 1045-1059, Smithsonian Institution Press, Washington, DC, USA, 1979.

[16] M. L. Buffington and S. I. Morita, "Not all oak gall wasps gall oaks: the description of Dryocosmus rileypokei, a new, apostate species of cynipini from california," Proceedings of the Entomological Society of Washington, vol. 111, no. 1, pp. 244253, 2009.

[17] J. A. Payne, R. A. Green, and C. D. Lester, "New nut pest: an oriental chestnut gall wasp in North America," Annual Report of the Northern Nut Growers Association, vol. 67, pp. 83-86, 1967.

[18] G. Brussino, G. Bosio, M. Baudino, R. Giordano, F. Ramello, and G. Melika, "Nuovo cinipide galligeno in Piemonte. Pericoloso insetto esotico per il castagno europeo," L'Informatore Agrario, vol. 37, pp. 59-61, 2002.

[19] J. Liljeblad and F. Ronquist, "A phylogenetic analysis of higherlevel gall wasp relationships (Hymenoptera: Cynipidae)," Systematic Entomology, vol. 23, no. 3, pp. 229-252, 1998.

[20] F. Ronquist and G. Nordlander, "Skeletal morphology of an archaic cynipoid, Ibalia rufipes (Hymenoptera: Ibaliidae)," Entomologica Scandinavica, supplement 33, pp. 1-60, 1989.
[21] R. Harris, "A glossary of surface sculpturing. State of California, Department of Food and Agriculture," Occasional Papers in Entomology, vol. 28, pp. 1-31, 1979.

[22] D. C. Dailey, "Synonymy of Dryocosmus attractans and Callirhytis uvellae," The Pan-Pacific Entomologist, vol. 45, no. 2, pp. 132-134, 1969.

[23] D. C. Dailey and C. M. Sprenger, "Synonymy of Andricus gigas and the bisexual generation of Andricus crenatus (Hymenoptera: Cynipidae)," The Pan-Pacific Entomologist, vol. 49, no. 3, pp. 188-191, 1973.

[24] G. Melika and W. G. Abrahamson, "Review of the world genera of oak cynipid wasps (Hymenoptera: Cynipidae, Cynipini)," in Parasitic Wasps: Evolution, Systematics, Biodiversity and Biological Control, G. Melika and Cs. Thuróczy, Eds., pp. 150-190, Agroinform, Budapest, Hungary, 2002.

[25] W. Beutenmueller, "Descriptions of new Cynipidae," The Canadian Entomologist, vol. 49, pp. 345-349, 1917.

[26] A. Aebi, K. Schonrogge, G. Melika et al., "Parasitoid recruitment to the globally invasive chestnut gall wasp Dryocosmus kuriphilus," in Galling Arthropods and Their Associates, K. Ozaki, J. Yukawa, T. Ohgushi, and P. W. Price, Eds., pp. 103122, Springer, Tokyo, Japan, 2006.

[27] G. Melika, G. Csoka, and J. Pujade-Villar, "Check-list of oak gall wasps of Hungary, with some taxonomic notes (Hymenoptera: Cynipidae, Cynipinae, Cynipini)," Annales Historico-Naturales Musei Nationalis Hungarici, vol. 92, pp. 265-296, 2000.

[28] J. Pujade-Villar, P. Ros-Farré, and G. Melika, "Revision of the genus Chilaspis Mayr, 1881 (Hymenoptera: Cynipoidea: Cynipidae)," Annales de la Société Entomologique de France, vol. 39, no. 2, pp. 167-178, 2003.

[29] E. Azizkhani, G.-R. Rasoulian, A. Kharazi-Pardel et al., "New species of oak gall wasps from Zagross Mountains of Iran (Hymenoptera: Cynipidae: Cynipini)," Folia Entomologica Hungarica, vol. 67, pp. 161-197, 2006.

[30] M. Tavakoli, G. Melika, S. E. Sadeghi et al., "New species of oak gallwaps from Iran (Hymenoptera: Cynipidae: Cynipini)," Zootaxa, no. 1699, pp. 1-64, 2008.

[31] Z. Ács, G. Melika, Z. Pénzes, J. Pujade-Villar, and G. N. Stone, "The phylogenetic relationships between Dryocosmus, Chilaspis and allied genera of oak gallwasps (Hymenoptera, Cynipidae: Cynipini)," Systematic Entomology, vol. 32, no. 1, pp. 70-80, 2007.

[32] D. M. Drown and J. M. Brown, "Molecular phylogeny of North-American oak-galling Cynipini (Hymenoptera: Cynipidae) supports need for generic revision," Gen. Tech. Rep. NC199., U.S. Department of Agriculture, Forest Service, St. Paul, Minn, USA, 1998.

[33] J. Liljeblad, F. Ronquist, J. L. Nieves-Aldrey et al., "A fully web-illustrated morphological phylogenetic study of relationships among oak gall wasps and their closest relatives (Hymenoptera: Cynipidae)," Zootaxa, no. 1796, pp. 1-73, 2008. 

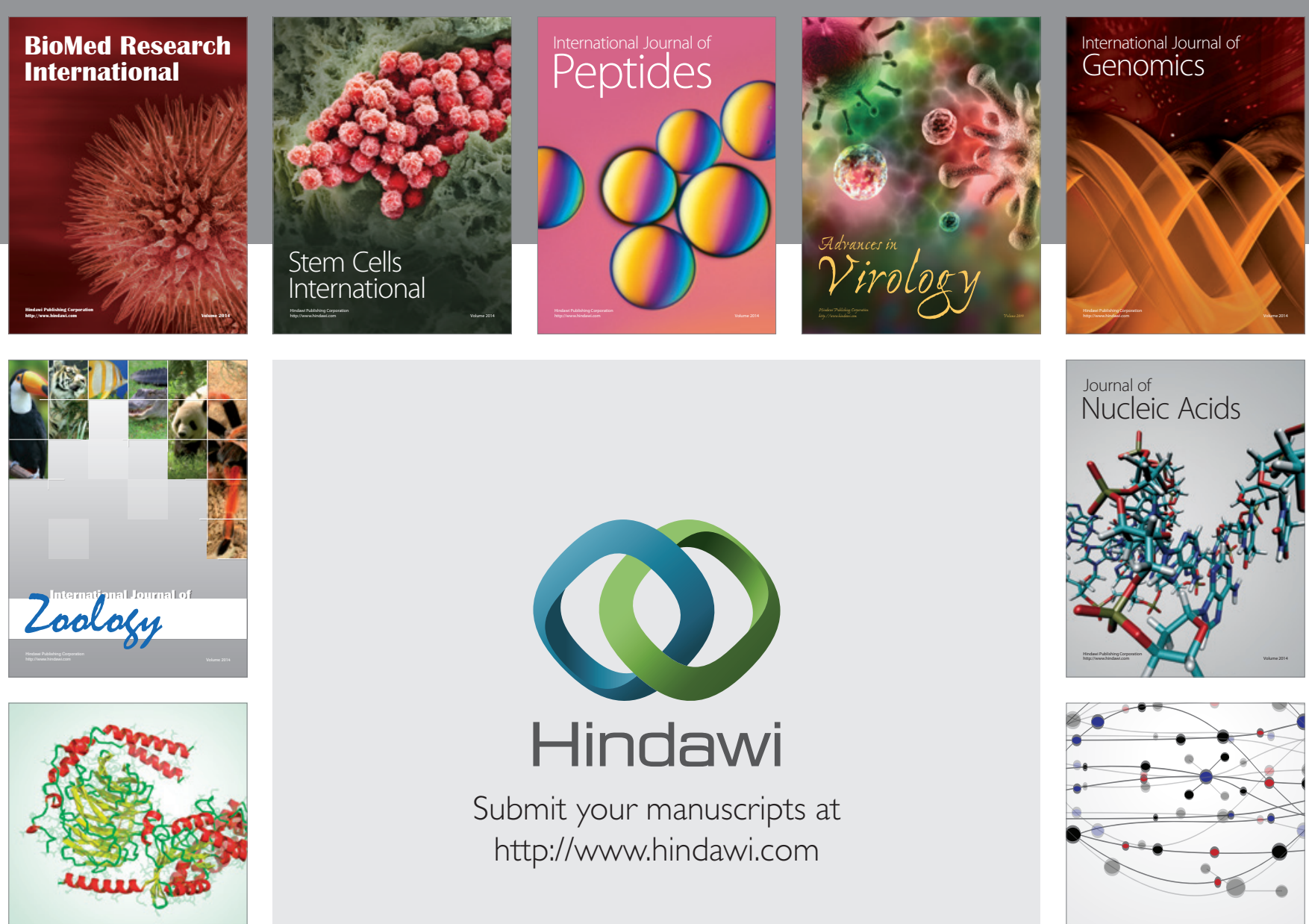

Submit your manuscripts at

http://www.hindawi.com

Signal ${ }^{\text {Jumal }}$ Transduction
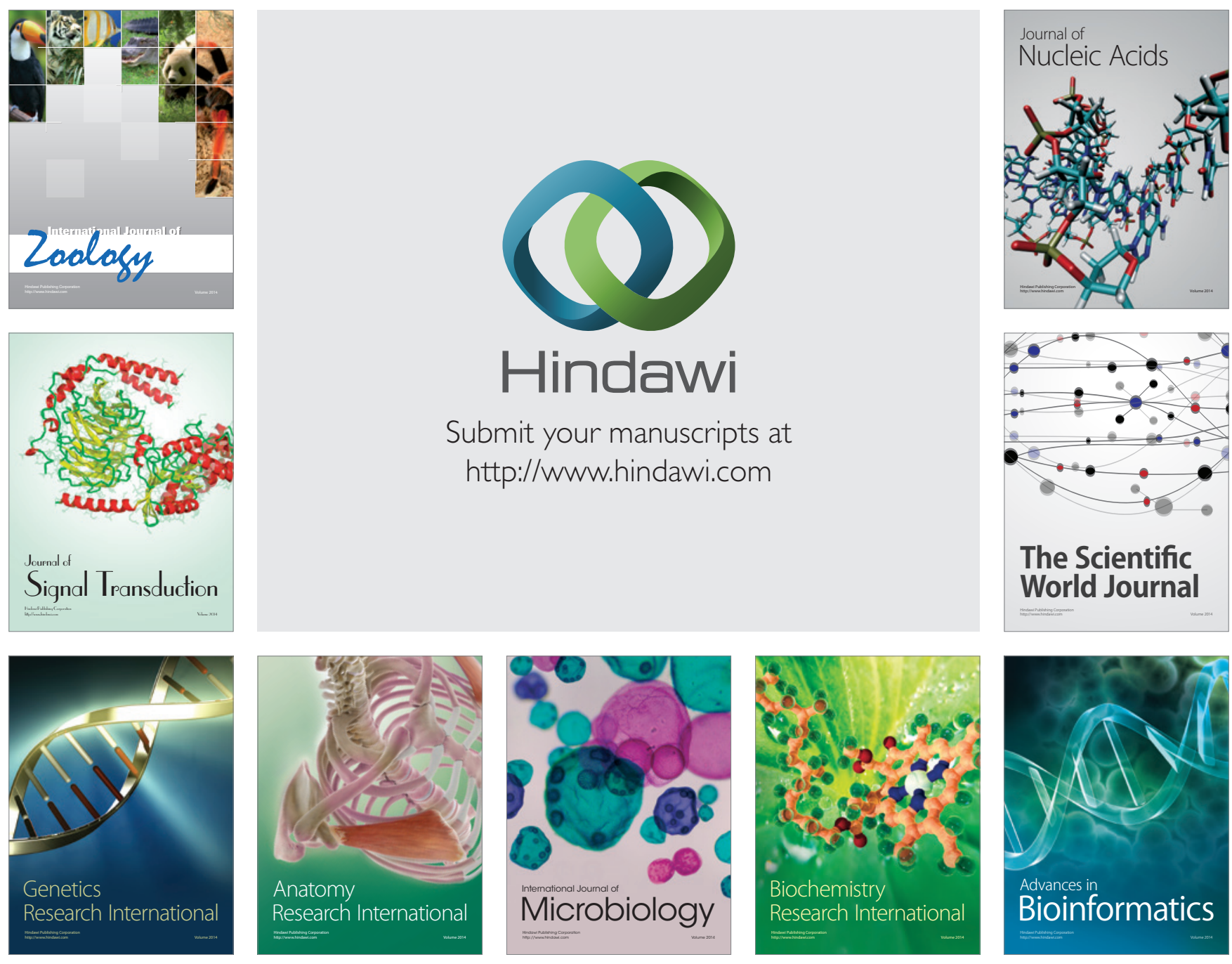

The Scientific World Journal
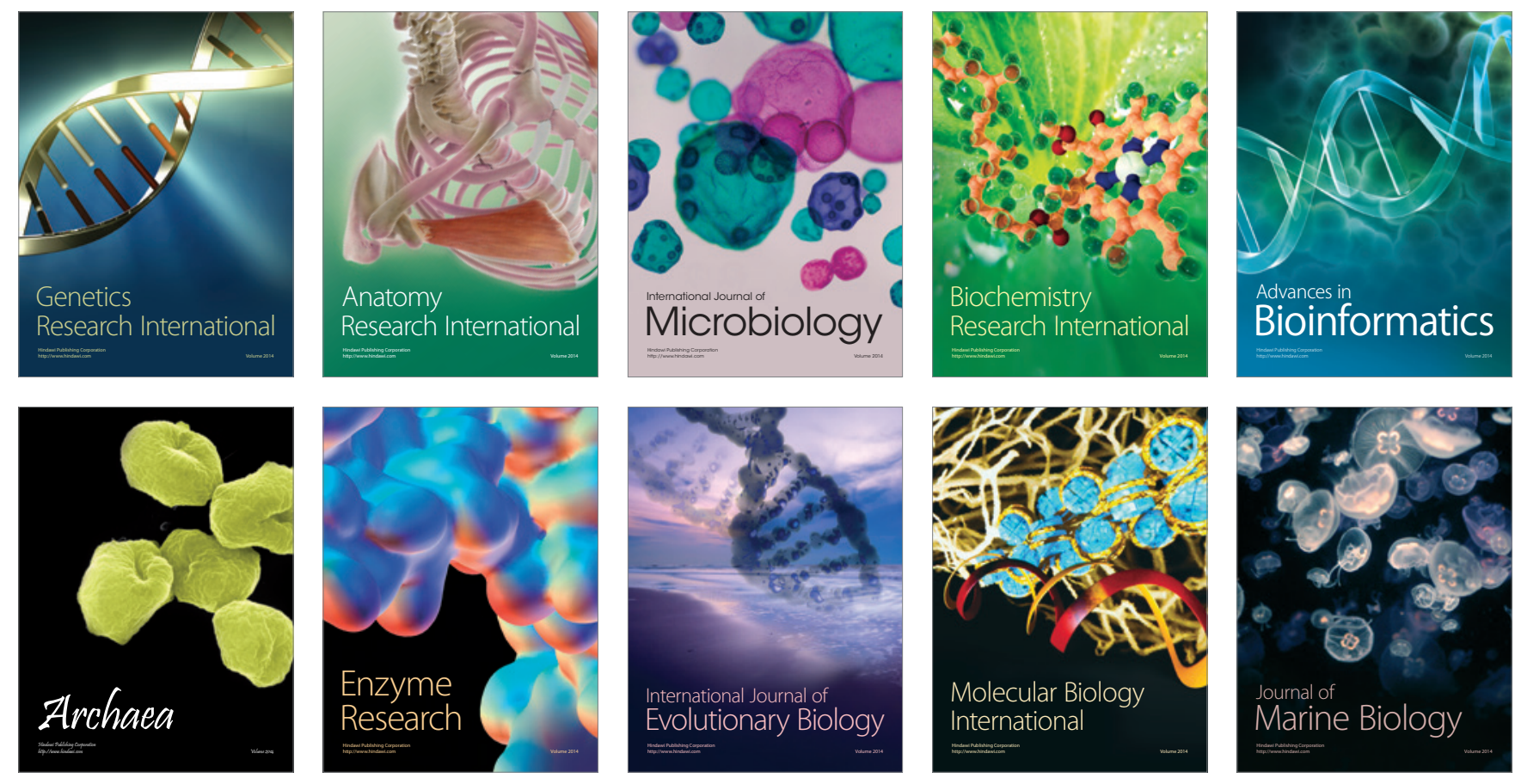